\title{
Reglementierte Erinnerung. Das Forum Romanum unter Augustus als Ort kontrollierter Kommunikation'
}

\section{Der öffentlich-repräsentative Raum als geformte und zugleich formende Bühne politischer Kommunikation}

Wie jede Stadt konstituiert sich das Rom der Kaiserzeit aus der Kombination strukturell verschiedener urbaner Räume, die auf unterschiedliche Funktionen und Bedürfnisse städtischen Lebens ausgerichtet sind (Abb. I). Diese einzelnen Räume - seien es politische, religiöse, ökonomische oder private Räume - sind einerseits Bühne für diejenigen Formen der Kommunikation, Interaktion und Repräsentation, welche für das sich hier abspielende Leben jeweils konstitutiv sind. Zugleich aber bestimmen, lenken und prägen diese Räume auch ihrerseits wiederum das sich in ihnen abspielende Leben durch ihre spezifische architektonische und überhaupt materielle Formung. ${ }^{2}$ Dieses wechselseitige Zusammenspiel von materiell geformtem Raum und sozialem Raum gilt in besonderem Ausmaß dort, wo ein gesteigertes Interesse an der Lenkung, Beeinflussung oder gar Kontrolle der sich hier vollziehenden sozialen Kommunikation besteht. Hierzu zählen vor allem die Räume des öffentlich-politischen Lebens - als diejenigen Räume, in denen seitens der Institutionen der Macht die größte Energie aufgewendet wird, um die Strukturen der politischen Macht zu repräsentieren und die politischen Diskurse zu lenken und zu kontrollieren. ${ }^{3}$

Die folgenden Ausführungen wollen den Blick auf eben dieses Funktionieren des öffentlich-politischen Raumes lenken. Dabei wird das Funktionieren aus der Perspektive der materiellen Formung des Raumes beleuchtet: Wie wird der Raum als Bühne der politischen Kommunikation inszeniert? Und wie wird mittels seiner architektonischen und monumentalen Ausgestaltung das hier waltende diskursive Klima beeinflusst und gelenkt?

\footnotetext{
I Die folgenden Überlegungen sind im Rahmen meines Forschungsprojektes „Gegenwart und Vergangenheit im Dialog: Konstituierung und Wandel des urbanen Raumes im kaiserzeitlichen und spätantiken Rom“ entstanden. Für anregende Diskussionen hierbei danke ich den Kollegen unserer Forschergruppe Topoi C-IV sowie den Teilnehmern der Tagung, namentlich vor allem Franz Alto Bauer, Stefan Freyberger und Christoph Klose. Für Unterstützung bei der Beschaffung von Photos danke ich ferner Bernhard Weisser (Berlin) und Reinhard Förtsch (Köln), für kritische Lektüre des Manuskripts Jessica Bartz.

$2 \mathrm{Zu}$ diesem grundlegenden Ansatz der Architektursoziologie weiterführend: Schäfers (2003); Delitz (2009); Delitz (20I0); Fischer u. Delitz (2009); Trebsche, Müller-Scheeßel u. Reinhold (2010).

3 Zum engen Zusammenspiel zwischen der Gestaltung des öffentlichen Raumes und seiner, Benutzung‘ als Bühne der öffentlich-politischen Kommunikation zuletzt eindrücklich am Beispiel von Rom: Hölscher (2006b) passim, bes. I87, I92-I98; sowie am Beispiel des politischen Platzes generell: Nova u. Jöchner (2010).
} 


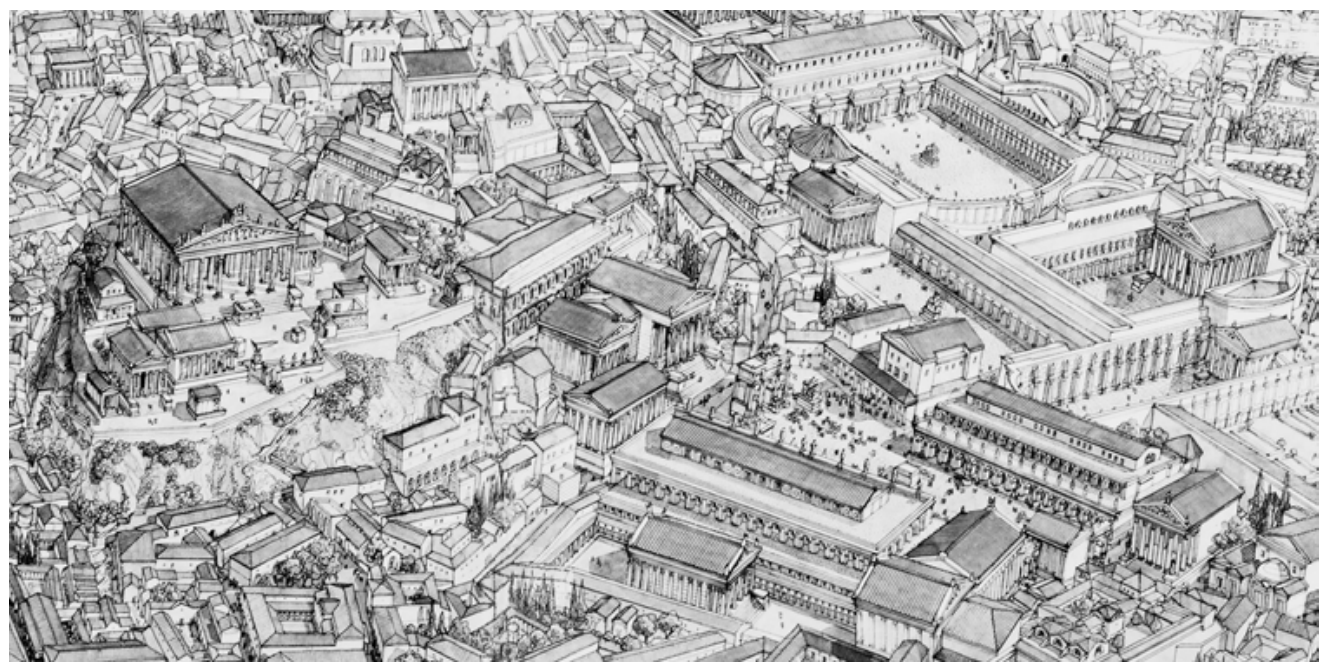

Abb. 1 | Stadtmitte des kaiserzeitlichen Roms mit Capitol, Forum Romanum und Kaiserfora, zeichnerische Rekonstruktion J.-Cl. Golvin

Ausgangspunkt meiner Diskussion ist das Forum Romanum, das ursprüngliche politische Zentrum der Stadt (Abb. 2-5).4 Als Bühne des politischen und öffentlichen Lebens wirkte das Forum einerseits durch seine architektonische Formung, mit den verschiedenen Bauten, Tempeln, Basiliken, etc., die den Platz des Forums rahmten und ihn dadurch räumlich definierten, - sowie andererseits durch die innere Strukturierung der Platzfläche mit den Rednertribünen, den Versammlungsstätten und Altären. All diese Bauten und Platzstrukturen prägten durch ihre jeweilige Bespielung mit bestimmten religiösen Ritualen oder politischen Prozessen den Charakter des Forums als Ort öffentlich-politischer Kommunikation. Hinzu kamen schließlich die Monumente, die im Bereich des Forums errichtet waren: Ehrenstatuen, Siegesdenkmäler und Memorialmonumente, welche als symbolische Male der Erinnerung und des Gedenkens ihrerseits ideelle bzw. ideologische Vorstellungen in den urbanen Raum herein holten, welche diesem zunächst nicht in dieser Prägnanz eigen waren. ${ }^{5}$ Die Bespielung des öffentlich-politischen Raumes durch solche

4 Allgemein zur architektonischen Formung (inklusive ihres diachronen Wandels) sowie zur Bespielung des Forum Romanum als politisch-repräsentatives Zentrum der Stadt Rom: Zanker (I972); Coarelli (I983 \& I985); Giuliani u. Verduchi (I995); Purcell (I995); Köb (2000) I5-20I; Kissel (2004); Hölscher (2006a); Freyberger (2009a); Freyberger (2009b). - Neben den Darstellungen zur Gesamtformung und Gesamtgeschichte des Forums exemplarisch zu einzelnen Strukturen: Carafa (I998); Freyberger (2009c); Giuliani u. Verduchi (I987); Muth (2009); sowie zu einzelnen Epochen: Patterson (I992) I90-I94; Bauer (I995) 6-79, IOI-I4I; Muth (20I0 \& 20II). 5 Zur Geschichte und Wirkungsmacht der Erinnerungsmonumente auf dem Forum grundlegend: Hölscher (I978); Lahusen (I983) I2-22; Sehlmeyer (I999a) passim; Hölscher (200I) I87-I88, I89-I94, 206-207, 207-209; Walter (2004) I3I-I54; Hölkeskamp (2004) I42-I44, I5I-I65, I73-I75, I90-I92; Schmuhl (2008) passim, bes. 247-25I, 262-264; Hölkeskamp (im Druck); generell zur Rolle von Bildwerken für die diskursive Aufladung der öffentlichen Räume Roms s. auch Hölscher (2006b) passim, bes. I87, I94-I97, I98-I99. 


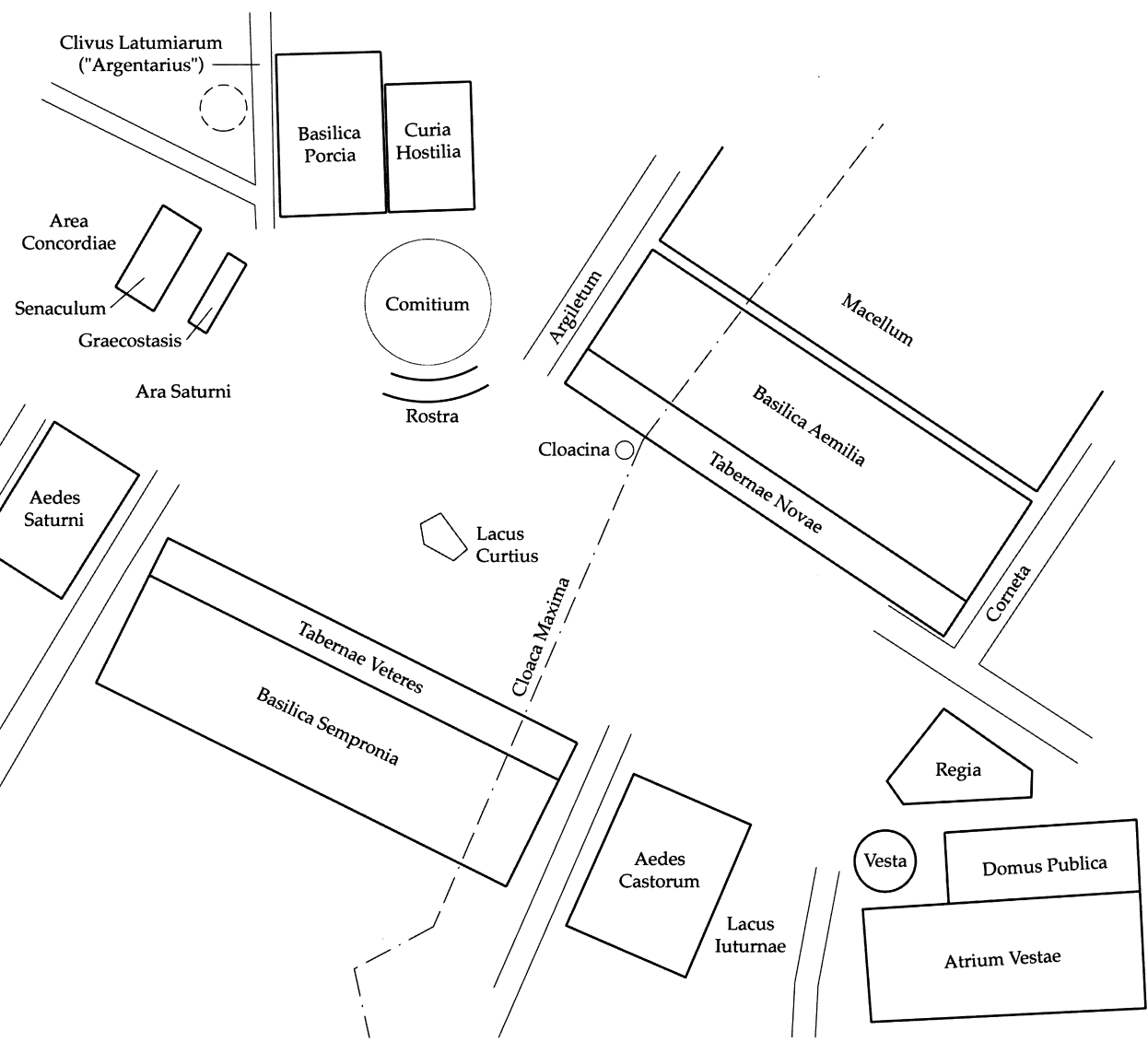

Abb. 2 | Plan des Forums in der späten Republik (2. Jahrhundert v. Chr.)

Monumente, deren Wirkungskraft vor allem in ihrer ideellen Aufladung lag, bewirkte somit eine nochmals intensivierte und zugleich zugespitzte Anreicherung des diskursiven Klimas in diesem Raum. Und genau hierin, in der Auswahl der Monumente und der dadurch erzielten Anreicherung des diskursiven Klimas, lagen dann auch die zentralen Mechanismen, die es besonders erlaubten, den Raum des Forums als Bühne öffentlichpolitischer Kommunikation mit zu determinieren, zu lenken und letztlich auch zu kontrollieren.

Jener Aspekt soll im Zentrum der folgenden Diskussion stehen: die Rolle der Monumente bei der Formung des Forums als eines Ortes politischer Kommunikation. Dabei werden wir uns ein Kapitel aus der Geschichte der monumentalen Bespielung des Forums herausgreifen, das eine merkliche Zäsur in der Instrumentalisierung der Monumente greifbar werden lässt, das allerdings bislang in seiner Bedeutung noch keine ausreichende Diskussion erfahren hat. Es geht um die Geschichte der Monumente an der Wende von der 


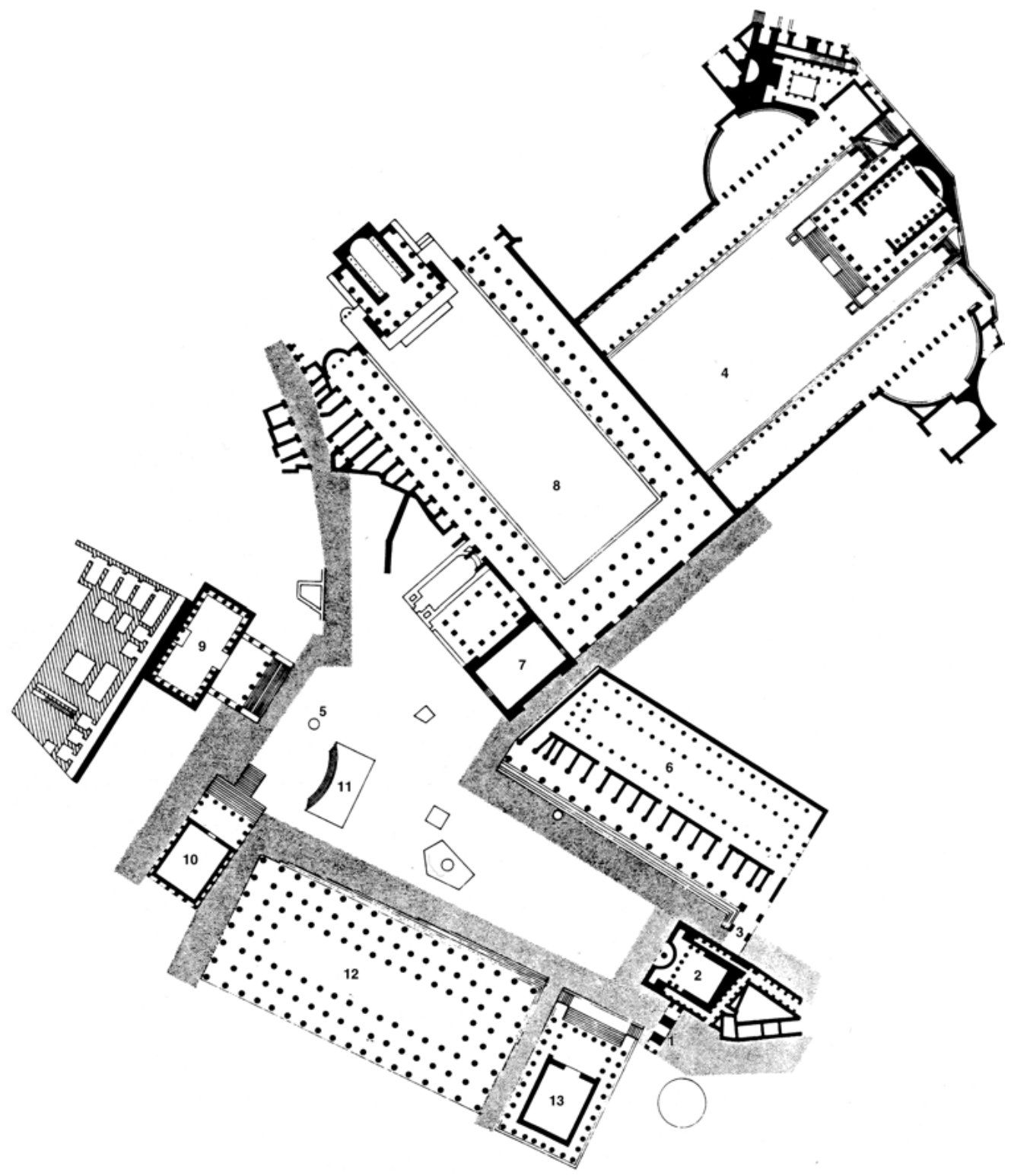

Abb. 3 | Plan des politischen Zentrums unter Augustus, mit Forum Romanum, Caesarforum und Augustusforum (I4 n. Chr.) 
späten Republik zur frühen Kaiserzeit: eine Zeit, als die Monumente am Forum in eine Krise gerieten und sich als einziger Ausweg hieraus eine grundlegende Neustrukturierung in der Bespielung des Forums mit Monumenten ergab. ${ }^{6}$

In drei Schritten wollen wir uns dieses Kapitel erschließen: Damit wir genauer verstehen, was an der Wende von der Republik zur Kaiserzeit geschieht, werden wir zunächst kurz die Situation der Monumente zuvor am republikanischen Forum betrachten; danach folgt die Krise der Monumente oder das, was sich dahinter verbirgt; und als dritter Schritt ist dann nach den Konsequenzen zu fragen, die zu einem neuen Umgang mit den Monumenten im öffentlich-politischen Raum führten - und zu einem neuen Einsatz von Memorialmonumenten bei der Ausgestaltung der Orte politischer Kommunikation.

\section{Die Rolle der Monumente am republikanischen Forum: Ideelle Aufladung des diskursiven Klimas}

Beginnen wir mit dem ersten Schritt: der vorausgehenden Situation am republikanischen Forum. Ab dem mittleren 4. Jahrhundert v. Chr. lässt sich am Forum die Errichtung von politischen Monumenten, Siegesdenkmälern, Ehrenstatuen und Memorialstatuen greifen wodurch eine neue Stufe der Politisierung des Forums eingeläutet wird.7 Das Aufkommen politischer Monumente steht im unmittelbaren Zusammenhang mit der damaligen Etablierung der Nobilität: Die neue auf Leistung ausgerichtete Aristokratie suchte neue Formen der politischen Repräsentation und politischen Konkurrenz, welche dann wiederum auch das Gesicht des Forums als Bühne der politischen Kommunikation nachhaltig veränderten. ${ }^{8}$ Vor allem davon betroffen ist die Nordwest-Ecke des Forums, der Bereich des Comitiums als das eigentliche Zentrum der politischen Entscheidungsfindung im republikanischen Rom: Hier lagen die Curia, das Amtslokal des Senats, sowie das Comitium, die Stätte

6 Angesichts der intensiven Diskussion zum Wandel der Stadt Rom, und insbesondere des Forums, unter Augustus überrascht, dass dieser Aspekt noch keine grundlegende Erörterung gefunden hat (s. etwa Zanker [I972]; Zanker [I987] passim; Wallace-Hadrill [I993] 5I-55; Favro (I996) bes. I95-200, 273-276; Haselberger [2007] passim). Offensichtlich dominiert eine latente Erwartungshaltung, dass neben allen bekannten Neuerungen doch auch versucht wurde, das alte republikanische Erscheinungsbild am Forum nachhaltig zu bewahren, gemäß der von Augustus lancierten Ideologie der res publica restituta; und scheinbar gegenläufige Tendenzen wie etwa die Beschwörung der Vergangenheit am Augustusforum (dazu s.u.) haben wohl am Forum mit keinen anderen Strategien im Umgang mit der Vergangenheit rechnen lassen. Doch weisen die Befunde am Forum auf eine andere und komplexere Geschichte.

7 Die Errichtung von Siegesmonumenten und Ehrenstatuen am republikanischen Forum ist seit längerem Gegenstand ausführlicher Erforschung. Grundlegend hierzu: Hölscher (I978) bes. 318-344; Lahusen (I983) I2-22 und passim; Sehlmeyer (I999a) 48-66, 83-IO9, IIO-I4I; Hölscher (200I) I88-I94; Walter (2004) I3I-I54, I57-I60; Hölkeskamp (2004) I37-I65, I73-I75; - ausführliche Auflistungen der Monumente: Lahusen (I983) I2-20; Sehlmeyer (I999a) passim; Coarelli (I999a) 2I2; Schmuhl (2008) passim.

8 Zur Verortung des Phänomens einer aufkommenden politischen Erinnerungskultur im historischen Kontext grundlegend: Hölscher (I978) bes. 348-357; Hölscher (200I) I88-I89; Hölkeskamp (2004) bes. I58-I65, I69-I98; Walter (2004) I32. 


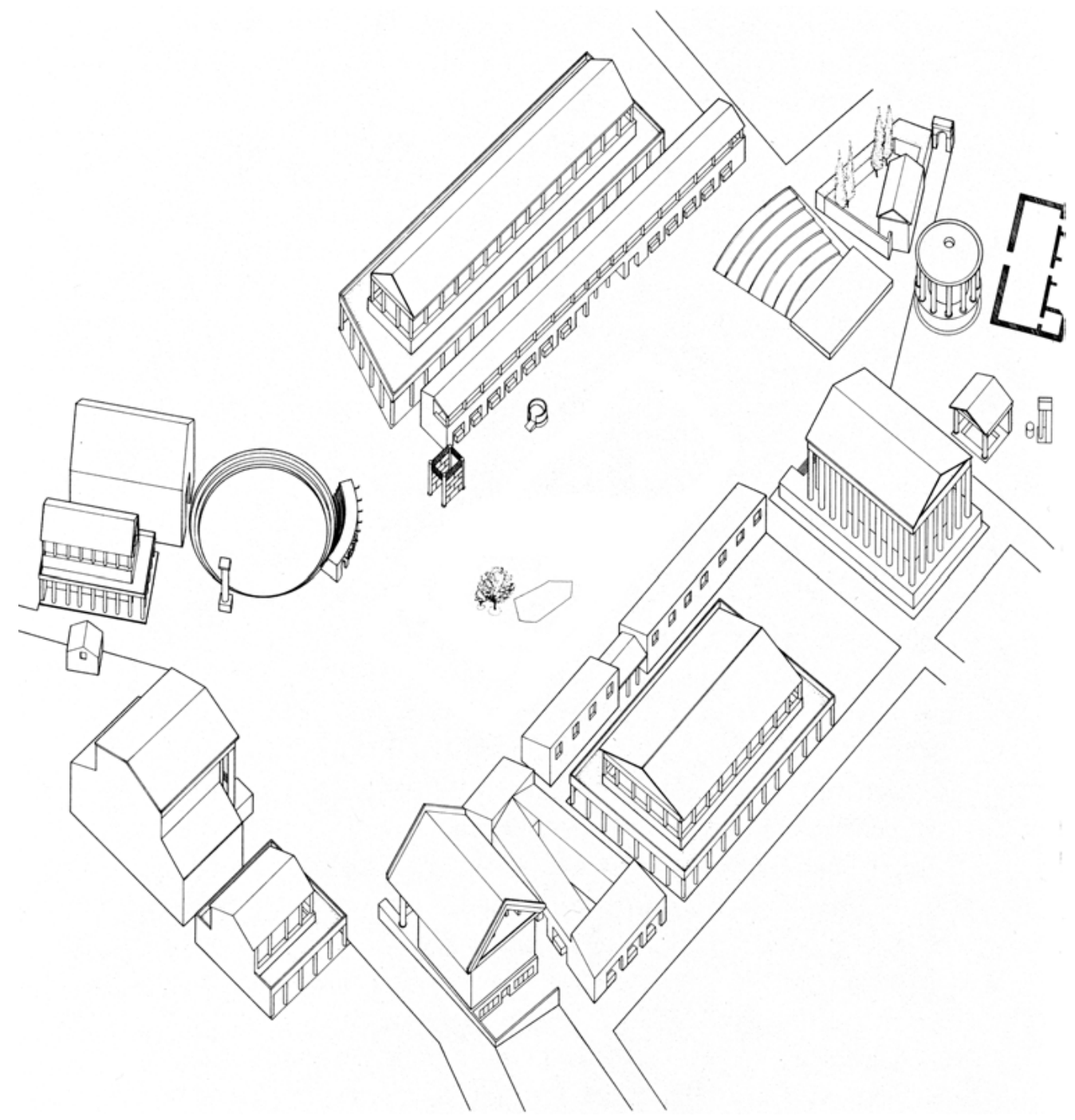

Abb. $4 \mid$ Rekonstruktion des republikanischen Forums im 2. Jahrhundert v. Chr. 


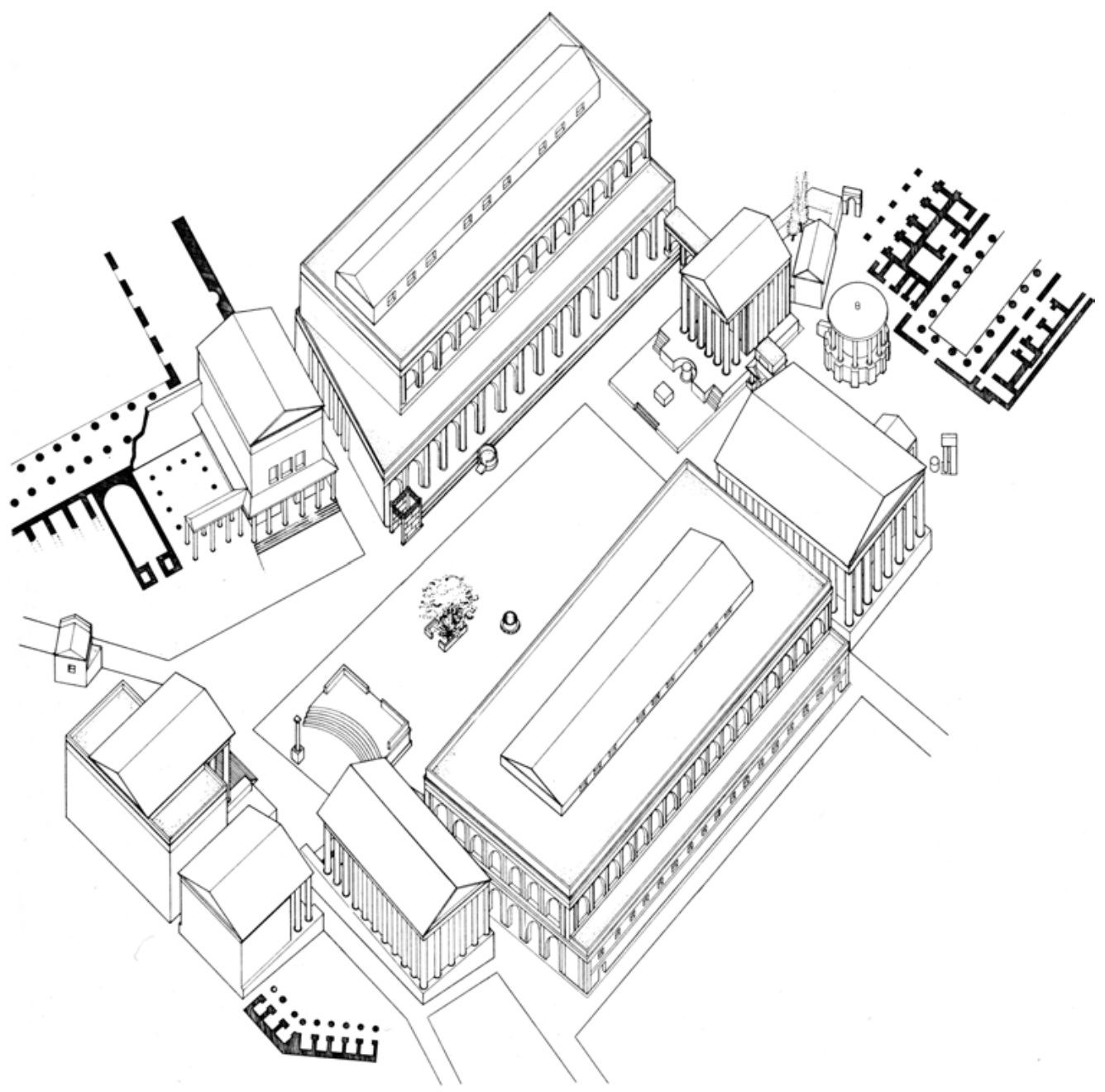

Abb. 5 | Rekonstruktion des frühkaiserzeitlichen Forums im I. Jahrhundert n. Chr. 


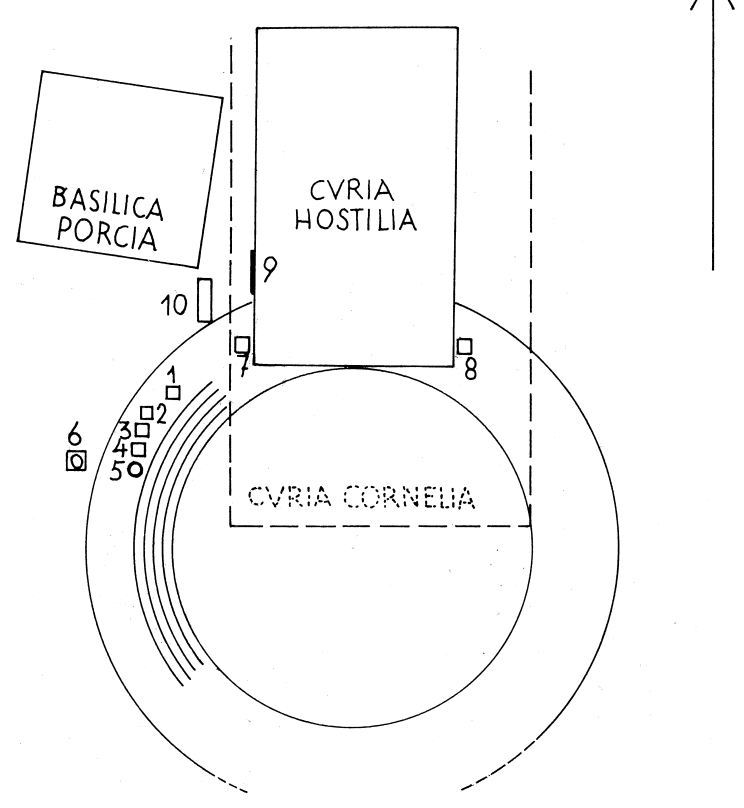

Abb. 6 | Plan des Comitiums in der mittleren und späten Republik mit Rekonstruktion der dort aufgestellten Monumente nach F. Coarelli (Nr. I: Statue des Attus Navius; 2: Ficus Ruminalis; 3: Statue der Lupa; 6: Columna Maenia; 7-8: Statuen des Pythagoras und des Alkibiades).

der Volksversammlung (Abb. 2, 4, 6). Konsequenterweise wurden genau in diesem Bereich dann auch die ersten politischen Monumente errichtet. Während man zuvor Siegesbeuten im Sinn von Weihgeschenken in den Heiligtümern der Stadt gestiftet hatte, kam es im Jahr 338 erstmals zu einer Aufstellung einer solchen Siegesbeute im öffentlich-profanen Bereich, womit das erste politische Siegesdenkmal in Rom Einzug hielt: Damals ließ der siegreiche Feldherr C. Maenius die Rednertribüne am Comitium mit den Rammspornen der erbeuteten Flotte von Antium, den rostra, schmücken, wovon die Rednertribüne dann auch bekanntlich ihren Namen (Rostra) erhalten sollte. ${ }^{9}$ Damit war der Startschuss für die Errichtung von Siegesdenkmälern und Ehrenstatuen für verdiente Politiker und Feldherrn gegeben. In dichter Folge entstanden im Bereich des Comitiums weitere Siegesdenkmäler sowie Ehrenstatuen: Noch im selben Jahr wurde eine Ehrensäule für C. Maenius errichtet ${ }^{10}$, weiterhin (umstritten, ob auf dieser Säule) eine Reiterstatue für eben jenen

9 Anbringung der rostra an der Rednertribüne durch C, Maenius als erstes politisches Denkmal in Rom: Hölscher (I978) 3I8-3I9; Coarelli (I983) I45-I46; Coarelli (I993a) 3II; Carafa (I998) I43-I47; Coarelli (I999a) 2I2; Hölscher (200I) I9I; Hölkeskamp (2004) I5I, I73; Schmuhl (2008) 74-77.

Io Columna Maenia: Welin (I953) I30-I5I; Hölscher (I978) 338-339; Coarelli (I983) I4I, I50; Lahusen (I983) 67-68; Coarelli (I985) 39-53; Bergemann (I990) I56; Coarelli (I993a) 310-3II; Torelli (I993); Jordan-Ruwe (I995) 54-57; Coarelli (I999a) 2I2; Sehlmeyer (I999a) 50 mit Anm. 4I, 53-57; Hölscher (200I) I9I mit Anm. I6; Hölkeskamp (2004) I6I, I74; Walter (2004) I40; Schmuhl (2008) 77-78. - Die jüngeren Diskussionen tendieren dazu, die früher angenommene Identität von Ehrensäule und Reiterstandbild des Maenius anzuzweifeln und von 
Abb. 7 | Darstellung der Reiterstatue des Q. Marcius Tremulus, Denar des L. Marcius Philippus, 56 v. Chr.

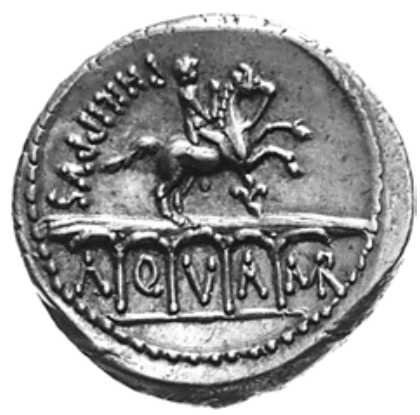

C. Maenius ${ }^{\mathrm{II}}$, ferner eine weitere Reiterstatue für L. Furius Camillus ${ }^{\mathrm{I2}}$, 306 dann eine Reiterstatue für Q. Marcius Tremulus beim Dioskurentempel ${ }^{\mathrm{I3}}$ (Abb. 7), im 3. Jahrhundert (260) eine weitere, mit Schiffsschnäbeln geschmückte Ehrensäule (columna rostrata) für C. Duilius ${ }^{\mathrm{I} 4}$, wiederum beim Comitium, von der Reste bei den Ausgrabungen noch gefunden wurden (Abb. 8-9); schließlich erhalten auch die Gesandten Roms, die in ihrer Funktion als Gesandte zu Tode gekommen waren, Ehrenstatuen auf bzw. bei der Rednertribüne ${ }^{\mathrm{I5}}$. Doch sind das nicht die einzigen Monumente, die damals begannen, das Comitium

zwei getrennten Monumenten beim Comitium auszugehen. Zum Teil wird gar die Funktion der Columna als Ehrensäule in Frage gestellt, besonders betont s. Sehlmeyer (I999a) 55, der eine Errichtung der Säule für primär praktische Zwecke als Zeitzeiger erwägt; dies steht jedoch im Widerspruch zu Plin. nat. 34,20, der die Columna des Maenius eindeutig als Beispiel eines Ehrenmonuments einführt.

II Reiterstatue des C. Maenius: Welin (I953) I38-I40; Hölscher (I978) 338-339; Lahusen (I983) I5, 57, 59, 67-68; Coarelli (I985) 43-44; Bergemann (I990) I56; Jordan-Ruwe (I995) 55; Papi (I995) 229; Coarelli (I999a) 2I2; Sehlmeyer (I999a) 48-50; Hölscher (200I) I9I.

I2 Reiterstatue des L. Furius Camillus: Hölscher (I978) 338; Lahusen (I983) I5, 57, 59, 67-68; Bergemann (I990) I56; Coarelli (I999a) 2I2; Sehlmeyer (I999a) 48-52; Hölscher (200I) I9I; Hölkeskamp (2004) I6I. - Umstritten ist, ob es neben der Statue für L. Furius Camillus auch eine solche seines Großvaters, des berühmten M. Furius Camillus, in rostris gab; zur Diskussion s. Hölscher (I978) 338; Lahusen (I983) I5, 47, 67, 77; Sehlmeyer (I999a) 5I-52; Walter (2004) 399. Sehlmeyer (I999a) 52 erwägt, ausgehend von einer am Forum gefundenen kaiserzeitlichen (augusteischen?) Marmorplatte mit einem Elogium auf Camillus, dass hier in der Kaiserzeit eine Statue des legendären Camillus, zusammen mit solchen anderer Großen der Republik, aufgestellt worden sei; s. hierzu aber die differenziertere Diskussion um die Auswertung der Elogia-Funde bei Spannagel (I999) 3I9-32I mit Anm. 402.

I3 Reiterstatue des Q. Marcius Tremulus: Hölscher (I978) 339-340; Lahusen (I983) I9, 47, 57-58, 69; Bergemann (I990) I56; Papi (I995) 229-230; Sehlmeyer (I999a) 57-60; Hölscher (200I) I9I; Hölkeskamp (2004) I55-I56, I74; Schmuhl (2008) 78-79; Hölkeskamp (im Druck).

I4 Columna rostrata des C. Duilius: Welin (I953) I55, I70; Hölscher (I978) 340-34I; Lahusen (I983) I6 Anm. 73, 69, 83; Chioffi (I993); Jordan-Ruwe (I995) 53, 58-59; Coarelli (I999a) 2I2; Sehlmeyer (I999a) II7-II9; Hölscher (200I) I9I; Kondratieff (2004) 7-26; Hölkeskamp (2004) I52, I74; Schmuhl (2008) 84-87; Roller (2009) 219-229.

I5 Statuen der Gesandten: Hölscher (I978) 337; Lahusen (I983) I6, 78-79, 97-98, I34; Coarelli (I999а) 2І2; Sehlmeyer (I999a) 63-66; Hölscher (200I) I9I-I92 mit Anm. 20; Hölkeskamp (2004) I6I. Für drei Gesandtschaften werden derartige Ehrenstatuen überliefert: I) Tullus Cloelius, L. Roscius, Sp. Nautius und C. Fulcinius, die 438 von den Fidenaten getötet wurden; 2) P. Iunius und Ti. Coruncanius, die 229 von der Illyrier-Königin 


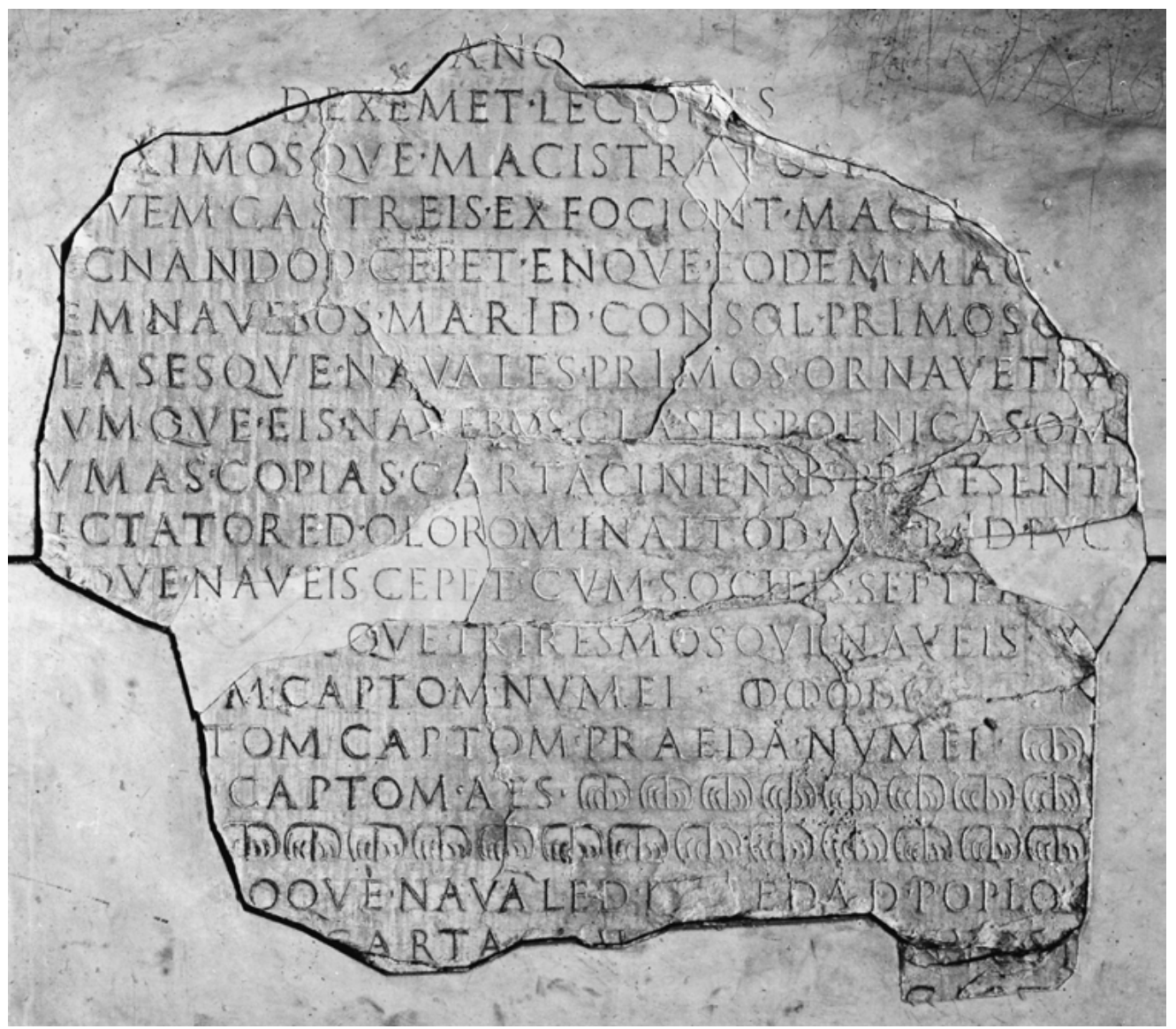

Abb. 8 | Reste des Inschriftenblocks der Columna rostrata des C. Duilius, die auf eine spätere (augusteische?) Restaurierung der Ehrensäule verweisen, Rom, Musei Capitolini, Museo Nuovo Capitolino, Inv.-Nr. 750.

Teuta ermordet wurden; sowie schon im 2. Jh. 3) Cn. Octavius, der I62 von König Antiochos getötet wurde. Während die Entstehungszeit der Ehrenstatuen für die beiden späteren Gesandtschaften unumstritten ist, wird die Datierung der Statuen der Fidene-Gesandten kontrovers diskutiert: Entweder geht man von einer Errichtung gleich nach ihrem Tod noch im 5. Jh. aus, was angesichts der sonstigen Geschichte der Ehrenstatuen in Rom überraschend früh erscheint; oder man postuliert eine deutlich spätere postume Aufstellung, im 4. Jh. oder gegebenenfalls sogar erst im 3. Jh., als konstruierten Prototyp und Vergleichspunkt für die Ehrenstatuen der Gesandten an die Illyrier, wobei dann wiederum das kleine Format der Statuen, von dem Plin. nat. 34,24 berichtet, überrascht, da dies eher auf ältere Statuenaufstellungen verweist. Die Frage nach der Datierung der ersten Gesandtenstatuen ist für unsere Diskussion hier sekundär: Wesentlich ist das Aufkommen einer Tradition, die entsprechende Ehrungen in der Folgezeit bedingte. - In der Gruppe der später aufgestellten Statuen verstorbener Gesandter ist schließlich noch die Statue des Ser. Sulpicius Rufus zu erwähnen, der 43 v. Chr. auf einer Gesandtschaft zu Antonius eines natürlichen Todes starb und dennoch mit einer solchen Statue geehrt wurde: Sehlmeyer (I999a) 252-253; Lahusen (I983) 79, 98, I34; Coarelli (1999a) 2 I2. 
Abb. 9| Rekonstruktion der Columna rostrata des C. Duilius, Rom, Museo dell Civiltà Romana.

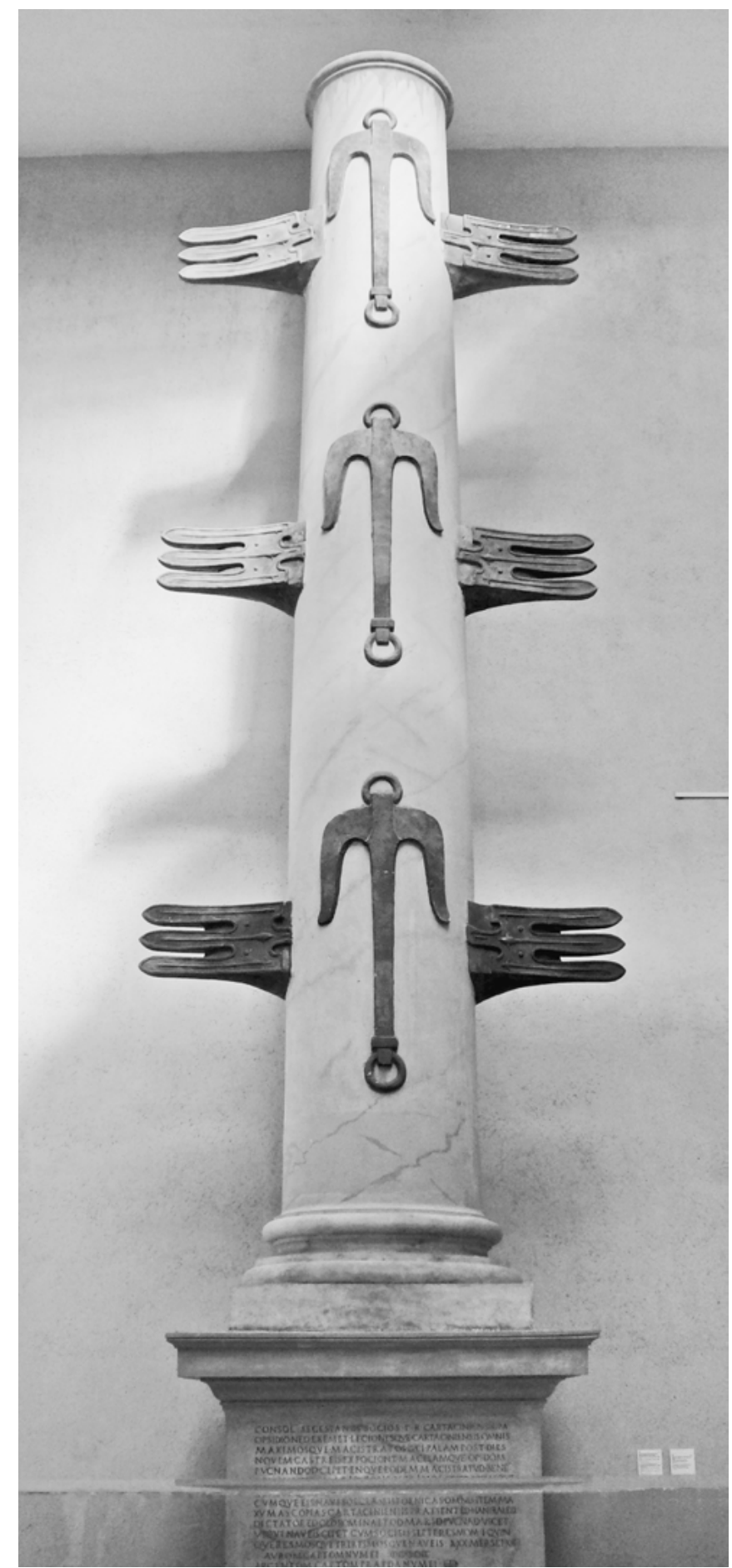


zu bevölkern. Mehr oder minder gleichzeitig wurden auch Memorialstatuen errichtet, die Personen der Vergangenheit postum ehrten und sie als Vorbilder der jeweiligen Gegenwart gegenüber präsent hielten. ${ }^{16}$ So wurde im Bereich des Comitiums eine Statue des Augurs Attus Navius errichtet, der sich hinsichtlich seiner pietas gegenüber dem Tyrannen Tarquinius Superbus ausgezeichnet hatte ${ }^{\mathrm{I} 7}$; ferner eine Statue des Horatius $\operatorname{Cocles}^{\mathrm{I} 8}$, als ebenfalls eines der Heroen der römischen Frühzeit, eventuell auch eine Statue des Mucius Scaevola $^{19}$, angeblich sogar eine solche des Porsenna ${ }^{2 \circ}$. Weiterhin wurde eine Statue des Hermodoros von Ephesos errichtet ${ }^{21}$, der bei der Auslegung der Zwölf-Tafel-Gesetze sich hervor getan hatte, ferner Statuen von Pythagoras und Alkibiades neben der Curia ${ }^{22}$, als Sinnbilder für sapientia und fortitudo. Im Jahr 296 wurde dann die berühmte Statue der $\operatorname{Lupa}^{23}$ (Abb. Io) aufgestellt, wohl neben der Ficus Ruminalis ${ }^{24}$, welche ebenfalls als gewichtiges Sinnbild den Gründungsmythos im politischen Zentrum Roms präsent hielt. Und schließlich erfahren wir sogar von einer Statue des Titus Tatius ${ }^{25}$, die eventuell beim

I6 Die Entstehung dieser Memorialstatuen wird in den antiken Quellen zum Teil bis in die Königszeit hoch gesetzt, was jedoch angesichts der sonst bezeugten Praxis von Ehrenstatuen unwahrscheinlich ist. Plausibler erscheint es, diese Statuen in Reaktion auf die aufkommende Tradition der Ehrenstatuen ab dem fortgeschrittenen 4. Jh. v. Chr. zu deuten, als konstruierte Vorbilder der Vergangenheit. Hierzu s. vor allem die grundlegende Diskussion bei Hölscher (1978) 327-337; Sehlmeyer (1999a) 67-I03, I09; Walter (2004) I43-I46.

I7 Statue des Attus Navius: Hölscher (I978) 232-233; Lahusen (I983) I3, 49; Coarelli (I985) 29-34; Coarelli (I993a) 310; Coarelli (I999b) 365-366; Sehlmeyer (I999a) 83-86; Hölscher (200I) I92-I93; Hölkeskamp (2004) I58-160.

I8 Statue des Horatius Cocles: Hölscher (I978) 334-335; Lahusen (I983) I3, 5I, 77, I09; Coarelli (I999b) 36r; Sehlmeyer (1999a) 92-96; Hölscher (200I) I93; Hölkeskamp (2004) I60, I74.

I9 Statue des Mucius Scaevola: Hölscher (I978) 334-335; Lahusen (I983) I3, 77; Sehlmeyer (1999a) 96-97; Sehlmeyer (I999b) 365; Hölkeskamp (2004) I74. - Zweifel an der Historizität der Statue unter Verweis auf Merkwürdigkeiten in ihrer literarischen Überlieferung: Sehlmeyer (1999a) 97.

20 Statue des Porsenna: Hölscher (I978) 332, 334-335; Lahusen (I983) I3; Sehlmeyer (I999a) IOI-IO2, Sehlmeyer (I999b) 368. - Ob es eine solche Statue des Porsenna bei der Curia überhaupt gab, ist unklar, zumal die literarische Überlieferung dieser Statue bei Plut. Publ. I9,9-IO nicht über jeden Zweifel erhaben ist. Im besten Fall könnte es sich hierbei um eine jüngere Konstruktion in Folge der Umbewertung der Figur des Porsenna in der späten Republik handeln; gegen die Historizität der Statue überhaupt spricht sich Sehlmeyer (I999a) IOI-IO2 aus.

2I Statue des Hermodoros von Ephesos: Hölscher (I978) 335-336; Lahusen (I983) I3, IO9; Coarelli (I999b) 36I; Sehlmeyer (1999a) 86-88; Hölscher (200I) I93; Hölkeskamp (2004) I60.

22 Statuen des Pythagoras und Alkibiades: Hölscher (I978) 336, 340; Lahusen (I983) I3; Coarelli (I985) II9-I23; Coarelli (I993a) 3II; Sehlmeyer (I999a) 88-90; Hölscher (200I) I93; Hölkeskamp (2004) I60, I9I.

23 Statue der Lupa: Dulière (I979) 58-62; Coarelli (I985) 33, 88-9I; Coarelli (I995) 249; Papi (I999); Sehlmeyer (I999a) I05-I06; Hölscher (200I) I92; Hölkeskamp (2004) I60; Walter (2004) I44. - Die Lokalisierung der von den Brüdern Cn. und Q. Ogulnii im Jahr 296 v. Chr. gestiftete Statue der Lupa mit den Zwillingen am Comitium (und nicht am Lupercal) ist bei Coarelli überzeugend argumentiert, unter Identifizierung der bei Liv. IO,23,II-I2 genannten Ficus Ruminalis mit derjenigen Ficus am Comitium, sowie unter Deutung des bei Plin. nat. I5,77 genannten miraculum ex aere bei der Ficus Ruminalis als die betreffende Statuengruppe der Lupa.

24 Ficus Ruminalis am Forum (wohl identisch mit der am Comitium bezeugten Ficus Navia): Coarelli (I985) 29-38; Coarelli (1995) 248-249, mit weiterer Literatur; Hölkeskamp (2004) I60.

25 Statue des Titus Tatius: Sehlmeyer (I999a) 8I mit verständlichem Zweifel an der Authentizität. Eine Statue des Titus Tatius beim Comitium bzw. der Via sacra, die zusammen mit einer des Romulus erwähnt und als gemeinsam rezipierte Statuengruppe eingeführt wird, ist lediglich bei Serv. auct. Aen. 8,64I überliefert (huius autem facti in sacra via signa stant, Romulus a parte Palatii, Tatius venientibus a rostris); hierbei würde es sich um 
Abb. 10 | Darstellung der römischen Wölfin mit den Zwillingen Romulus und Remus, im Hintergrund die Ficus Ruminalis, Denar des Sex. Pompeius, I37 v. Chr.

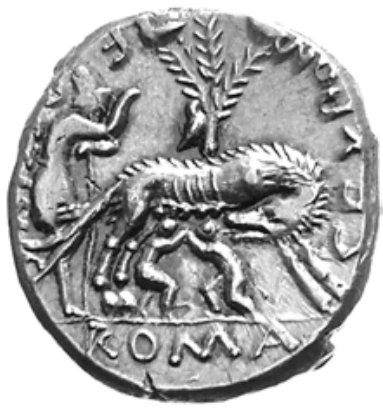

Comitium stand, sowie ebenfalls von einer des Romulus ${ }^{26}$, wobei beide Überlieferungen nicht völlig klar sind.

Insgesamt bevölkerten also mehrere Ehren- und Memorialstatuen seit dem mittleren 4. Jahrhundert den Bereich des Comitiums und des Forums ${ }^{27}$ - und hielten in diesem Raum der konzentrierten politischen Kommunikation verschiedenste exempla des vorbildlichen politischen Handelns präsent, als Orientierung, Maßstab und zugleich Herausfor-

eine ideell durchaus bedeutsame Statuengruppe handeln, die den mythischen Vertragsschluss zwischen Romulus und Titus Tatius in ihrer vermeintlich legendären Topographie verorten würde: eine solche Statuenaufstellung würde man jedoch auch bei anderen Autoren erwähnt erwarten, vor allem dort, wo eben der mythische Vertragsort mit konkreten Orten der Forumstopographie in Verbindung gebracht wird (Liv. I,I3; Dion. Hal. ant. 2,46,3; Plut. Rom. 19,7). Das Schweigen jedoch aller anderen Autoren lässt die Überlieferung bei Servius wenig glaubhaft erscheinen. Zumindest eine Aufstellung der Statuen in republikanischer Zeit scheint angesichts der literarischen Überlieferung ausgeschlossen; will man der Überlieferung bei Servius eine historische Aussagekraft beimessen, müsste man folglich eine spätere Statuenaufstellung in der Kaiserzeit, eventuell in augusteischer Zeit annehmen, als das Interesse an der mythischen Topographie am Forum eine neue Dimension gewann, dazu ausführlicher s.u.

26 Statue des Romulus: Sehlmeyer (1999a) 8I; als Pendant zu der des Titus Tatius bei Serv. Aen. 8,64I überliefert. Für diese Statue des Romulus gelten die gleichen Zweifel an der Authentizität bzw. Datierung in republikanische Zeit, wie sie für die Statue des Titus Tatius gerade besprochen wurden. - Nicht wesentlich glücklicher erscheint die Situation bei einer zweiten überlieferten Statue des Romulus als Tropaiophoros: Dion. Hal. ant. 2,54,2 berichtet von einer Triumphalquadriga und einer Statue des Romulus tropaiophoros daneben, die im Comitium gestanden hätten und die er als Weihung des Romulus selbst deutet. Auch hier verrät die Ikonographie der Triumphalquadriga, dass es sich hierbei eindeutig um ein späteres, eventuell augusteisches Konstrukt handelt, wobei unklar bleibt, ob es ein rein literarisches Konstrukt ist, oder ob in augusteischer Zeit eine solche Statue im Comitium aufgestellt wurde. Ausführlicher zu der gesamten Problematik: Lahusen (1983) I3 Anm. 42, 65; Sehlmeyer (1999a) 74-76, bes. 75-76 mit Anm. I93-I95; Sehlmeyer (I999b) 369.

27 Aufgelistet sind hier freilich nur diejenigen Statuen, die uns in den literarischen Zeugnissen überliefert sind. Daneben muss von einer unbekannten Ziffer weiterer Statuenerrichtungen ausgegangen werden. Aus dem mittleren 2. Jahrhundert erfahren wir von der Abräumung zahlreicher Statuen, die zuvor nicht auf Beschluss von Senat und Volk errichtet worden wurden (s.u.), ohne dass jedoch im Einzelnen Namen der Geehrten und Daten der Statuenerrichtungen bekannt sind. Diese ,Dunkelziffer 'illustriert anschaulich, wie punktuell unsere konkreten Kenntnisse der im Einzelnen errichteten Statuen - jenseits der tendenziell eher wenigen bekannten Monumente - letztlich sind. 
derung für die künftigen Generationen politisch ambitionierter Nobiles. ${ }^{28}$ Das heißt: Mit der Aufstellung dieser Statuen hielt sich die römische Gesellschaft die jeweils zentralen Themen ihres politischen Diskurses, Tugenden und Leistungen, permanent vor Augen und lenkte somit das diskursive Klima in diesem Raum der politischen Entscheidungsfindung gezielt in diejenigen Bahnen, die man in diesem Kontext als angemessen empfand. Und die errichteten Monumente funktionierten ihrerseits entsprechend, indem sie die betreffenden ideellen bzw. ideologischen Vorstellungen zur Disposition stellen, als Angebot und Anstoß für die sich im politischen Raum entfaltenden Diskurse.

Konsequent verdichtete sich in den folgenden Jahrhunderten die Phalanx der Monumente am Forum, weitere Ehrenstatuen kamen hinzu, bedingt dadurch, dass die aufgeheizte Konkurrenz unter den Nobiles auch die Repräsentation durch Ehrenstatuen zunehmend attraktiver werden ließ. ${ }^{29}$ Um die Mitte des 2. Jahrhunderts v. Chr. wurde die Praxis der Statuenaufstellung auf dem Forum offensichtlich derart inflationär gehandhabt, dass es zu einer Reinigung der Forumsfläche von allen nicht öffentlich verliehenen Ehrenstatuen kam. ${ }^{\circ}$ Eine weitere Stufe im angespannten Umgang mit den Statuenaufstellungen am Forum erreichte schließlich das I. Jahrhundert v. Chr.: Zum einen begann man nun, herausragende Politiker mittels exzeptioneller Statuenaufstellung nochmals besonders zu ehren, suchte also eine erneute qualitative Steigerung in der Inszenierung der Ehrenstatuen, indem man nun etwa Reiterstatuen bei oder auf den Rostra verlieh, so für Sulla ${ }^{3}$ (Abb. II), Pompeius ${ }^{2}$ sowie Caesar ${ }^{33}$ (Caesar scheint noch mit zwei weiteren Statuen auf den Rostra geehrt zu werden34); in der Zeit des 2. Triumvirats wurde schließlich die Verleihung von Reiterstatuen bei den Rostra fast zum alltäglichen Standard - Octavian35

28 Zur Wirkungsmacht der im politischen Zentrum aufgestellten Ehrenstatuen besonders: Hölscher (200I) I9I-I94, I99-20I; 206-207, 207-209; Hölkeskamp (2004) I58-I65, I9I-I92; Walter (2004) I3I-I33, I57-I60; Hölkeskamp (im Druck); Stein-Hölkeskamp (im Druck).

29 Zum historischen Kontext und den Veränderungen am Forum in der späten Republik: Hölscher (I980); Sehlmeyer (I999a), I42-I77, I78-203, 204-27I, bes. I52-I54, I7I-I73, 205-2II, 23I-238, 245-253; Hölscher (200I) 207-209; Hölkeskamp (2004) I56 Anm. 6I; I93-I95; Walter (2004) I57-I60.

30 Plin. nat. 43,30 berichtet für das Jahr 158 v. Chr. von der Abräumung von Privatstatuen am Forum: L. Piso prodidit M. Aemilio C. Popilio iterum cos. a censoribus P. Cornelio Scipione M. Popilio statuas circa forum eorum, qui magistratum gesserant, sublatas omnes praeter eas, quae populi aut senatus sententia statutae essent. Hierzu ausführlicher Sehlmeyer (I999a) I52-I54, I57-I58; Hölscher (200I) 208; Walter (2004) I60.

3I Reiterstatue des Sulla: Lahusen (I983) I5, 43, 56, 69, 98-99; Coarelli (I985) 238; Bergemann (I990) 34, I59; Papi (I995) 227-228; Coarelli (I999a) 2I2-2I3; Sehlmeyer (I999a) 204-209, 23I-232; Stein-Hölkeskamp (im Druck); - Stein-Hölkeskamp betont zurecht die innovative Qualität der Reiterstatue des Sulla als strukturelles Phänomen der Selbstdarstellung des Sulla in Rom.

32 Reiterstatue des Pompeius: Lahusen (I983) I5, 56; Bergemann (I990) 34, I60; Papi (I995) 227; Coarelli (I999a) 2I2; Sehlmeyer (I999a) 209-2II, 23I-232.

33 Reiterstatue Caesars: Lahusen (I983) I5, 56, 99; Bergemann (I990) 34, I6o; Papi (I995) 227; Coarelli (I999a) 2I2; Sehlmeyer (1999a) 232-234.

34 Weitere Ehrenstatuen Caesars am Forum: Lahusen (1983) I5, I4I; Sehlmeyer (1999a) 232-234.

35 Reiterstatue Octavians: Lahusen (I983) I5, 56-57, 59, 99, I39-I40; Zanker (I987) 46-48; Bergemann (I990) 34, I6I-I63; Papi (I995) 227, 230-23I; Sehlmeyer (I999a) 249-251. 


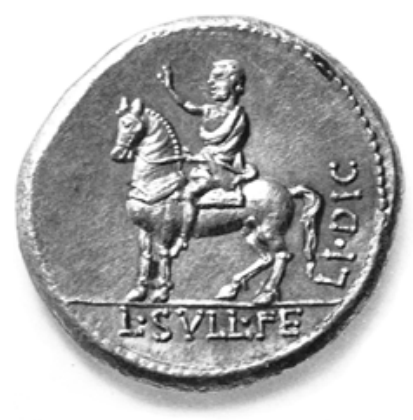

Abb. 11 | Darstellung der Reiterstatue des Sulla, Aureus des A. Manlius, 80 v. Chr.

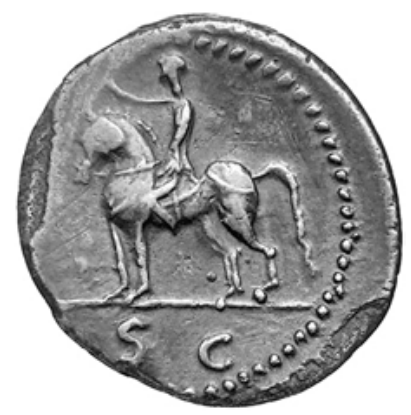

Abb. 12 | Darstellung der Reiterstatue des Octavian, Denar des Octavian, 43 v. Chr.

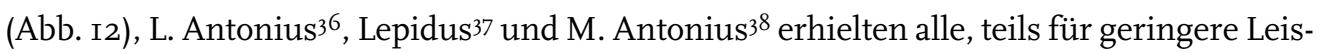
tungen und teils auch nur kurzzeitig, entsprechende Statuenehrungen. Gleichzeitig setzt im I. Jahrhundert v.Chr zum anderen auch ein angespannter Denkmälerkrieg ein: Statuen wurden umgestürzt, zerstört, oder bewusst wieder errichtet, jeweils als Akt politischer Manifestation und Parteinahme bzw. Verfolgung politischer Gegner - ein Prozess, der ebenfalls in der Zeit des 2. Triumvirats seinen Höhepunkt erfahren sollte, als das Aufstellen und schnelle Wieder-Abräumen von Ehrenstatuen fast zum politischen Alltag gehörte.39

Diese in mehrfacher Hinsicht hochgeheizte Situation im Umgang mit den Ehrenstatuen mag vielleicht der kausale Hintergrund für die Krise sein, in die die Monumente am Forum damals gerieten.

36 Reiterstatue des L. Antonius: Lahusen (I983) 20, 9I-92, 94; Bergemann (I990) I60; Papi (I995) 225; Sehlmeyer (I999a) 245-247; Hölkeskamp (im Druck).

37 Reiterstatue des M. Aemilius Lepidus: Lahusen (I983) 79-80, 99-100, I39; Bergemann (I990) I6I; Papi (I995) 224; Sehlmeyer (I999a) 247-249.

38 Statue des M. Antonius im Gespann auf den Rostra: Lahusen (i983) I7, 35, 65; Sehlmeyer (I999a) 25I; Schollmeyer (200I) I42, 209 .

39 Das Zerstören und Ausradieren von Erinnerungsmälern (sowie das Wiedererrichten) als Phänomen des aufgeheizten politischen Kampfes der ausgehenden Republik: Hölscher (I980) 356-357; Sehlmeyer (I999a) I96-I97, 2I7-2I8, 23I-232, 237-238, 248-249, 25I, 254; Hölscher (200I) 208-209; Hölkeskamp (2004) I56 Anm. 6r; Hölkeskamp (im Druck); Stein-Hölkeskamp (im Druck). Zu den einzelnen Monumenten am Forum, die der Zerstörung anheimfielen und teils wieder errichtet wurden, ausführlicher u. S. 22-23 mit Anm. 65 u. 66. 


\section{Die Last der ererbten Monumente: Reduktion der präsenten Vergangenheit unter Augustus}

Damit kommen wir zum zweiten Kapitel unserer Betrachtung. Die Forschung hat die Statuenaufstellungen auf dem republikanischen Forum intensiv diskutiert, doch hat sie sich dabei, bedingt durch ihre Fragestellungen, verständlicherweise mehr auf den Zeitpunkt der Aufstellung der Monumente konzentriert. $4^{\circ}$ Die weitere Geschichte der Monumente, vor allem die Frage nach der Dauer ihrer Aufstellung und eventuell ihrer Abräumung, ist hingegen kaum in den Blick genommen, geschweige denn systematisch erforscht worden.4 Überprüft man hierfür jedoch die literarischen und (wenigen) archäologischen Quellen, so offenbart sich eine im Grunde genommen überraschende Situation.

Eine Reihe der Monumente, die seit Jahrhunderten das Bild des Forums, und dort vor allem des Bereichs des Comitiums geprägt hatten, scheinen an der Wende von der Republik zur Kaiserzeit zu verschwinden. Die literarischen Quellen des ausgehenden I. vorchristlichen sowie des I. nachchristlichen Jahrhunderts, vor allem Plinius, Livius, und Dionysius $^{42}$ betonen oftmals bei ihren Nennungen republikanischer Statuen, dass diese zu ihrer Zeit nicht mehr stehen: So stehen am Forum der frühen Kaiserzeit nicht mehr die Säule des C. Maenius43, nicht mehr die Reiterstatue desselben C. Maenius44,

40 Hölscher (1978), Lahusen (1983), Hölscher (200I); Sehlmeyer (1999a), Schmuhl (2008).

4I Verdienstvoll ist der kurze Ausblick, in dem Sehlmeyer (I999a) 270-27I die weitere Geschichte der republikanischen Ehrenmonumente in der Kaiserzeit skizzenhaft diskutiert und damit als Thema markiert, ohne freilich die konstitutiven Strukturen genauer analysieren zu können. Bei den Einzelbesprechungen der Monumente verweist er zudem auf deren Fortbestand, soweit Informationen überliefert sind.

42 Zur literarischen Überlieferung der Statuen auf dem Forum und deren Einschätzung generell: Sehlmeyer (i999a) 39-43.

43 Plin. nat. 34,20 nennt die Columna Maenia zusammen mit der Columna rostrata des C. Duilius und betont nur bei Letzterer noch ihre Existenz auf dem Forum, woraus plausibel zu schließen ist, dass die Columna Maenia zur Zeit des Plinius nicht mehr stand. Ihre Erwähnung in mehreren Reden Ciceros (s. Zitate bei Coarelli [1985] 40-42) bezeugt hingegen ihre Existenz noch in der späten Republik. Am wahrscheinlichsten ist daher die Annahme, dass die Säule im Zuge der baulichen Eingriffe am Comitium unter Caesar bzw. Augustus verschwand, s. Welin (1953) I48; Sehlmeyer (I999a) 53 mit Anm. 60, 57.

44 Das Schicksal der Reiterstatue des C. Maenius (und damit zusammenhängend der des Furius Camillus) ist nur vage zu rekonstruieren. Soweit man die Reiterstatue des Maenius auf der Columna Maenia postuliert, gilt das für die Columna Maenia eben Gesagte. Trennt man jedoch beide, kann die Argumentation nur aus dem Schweigen der literarischen Quellen entwickelt werden - auch wenn eine solche argumentatio e silentio keine absolute Evidenz gewinnen kann, erlangt sie im Kontext der anderen Überlieferungen zu den sonstigen Monumenten am Forum dennoch hohe Plausibilität: Die Reiterstatuen des Maenius und Camillus sind allein bei Liv. 8,I3,9 bezeugt (für das Jahr 338: ... statuae equestres eis ... in foro ponerentur), ohne dass hieraus Informationen für die Dauer ihrer Existenz gewonnen werden können. Bedenkenswert erscheint die Tatsache, dass Plinius bei der verschiedentlichen Thematisierung früher Reiterstatuen (z. B. Plin. nat. 34,23;28) die des Maenius und des Camillus überhaupt nicht erwähnt, was man jedoch eigentlich eher erwarten würde, hätten sie zu seiner Zeit noch gestanden; dass er sie auch nicht unter den Statuen erwähnt, die einst standen, später aber abgeräumt wurden, könnte man auch dahin gehend interpretieren, dass beide Statuen vergleichsweise früh aus dem Horizont des Forums wieder verschwanden - Sehlmeyer (I999a) 49 Anm. 3I schlägt hierfür als möglichen Moment den Bürgerkrieg zwischen Sulla und Cinna vor. Unter der Voraussetzung, dass die Angabe bei Eutrop, die beiden Statuen hätten in rostris gestanden (Eutr. 2,7: Statuae consulibus ob meritum victoriae in rostris positae sunt), etwas Richtiges trifft, mag man als 
nicht mehr die des Furius Camillus ${ }^{45}$, nicht mehr die Statue des Hermodoros ${ }^{46}$, nicht mehr die des Alkibiades und des Pythagoras47, nicht mehr die Statue des Augurs Attus Navius $^{4}{ }^{8}$, nicht mehr ein Großteil der Statuen der ermordeten Gesandten49, nicht mehr die Reiterstatue des Marcius Tremulus ${ }^{5}$. Oder, um die Situation vom erhaltenen Bestand her $\mathrm{zu}$ formulieren: Was lediglich bestehen bleibt - außer natürlich den Reiterstatuen des Sulla (Abb. II), Pompeius, Caesar und Octavian (Abb. I2) 5 $^{\text {I }}$ - sind allein die Columna

weiteres Argument auf die Wiedererrichtung der Reiterstatuen des Sulla und des Pompeius bei den durch Caesar 44 v. Chr. verlegten Rostra verweisen (dazu ausführlich Sehlmeyer [I999a] 23I-232). Spätestens bei dem Umbau der Rostra hätten die Reiterstandbilder des Maenius und des Camillus, falls sie damals noch in rostris standen, versetzt werden müssen - und diese Aktion hätte wohl irgendeinen Niederschlag im literarischen Diskurs gefunden; dass jedoch auch in diesem Kontext von ihnen keine Rede ist, legt wiederum nahe, dass die beiden Reiterstatuen des Maenius und des Camillus damals schon nicht mehr existierten - vor diesem Hintergrund ist der Vorschlag Sehlmeyers (I999) 49, ihre Zerstörung in den bürgerkriegsartigen Wirren unter Sulla und Cinna zu vermuten, eine durchaus denkbare, wenn freilich auch nicht zu beweisende Option.

45 Für die Reiterstatue des Furius Camillus gilt die eben für die des Maenius geführte Argumentation.

46 Nach Plin. nat. 34,2I stand die Statue des Hermodoros zu Zeiten des Plinius nicht mehr: fuit et Hermodori Ephesii (sc. statua) in comitio; dem gegenüber stellt Plinius die Statue des Horatius Cocles, von der er ebd. explizit sagt, dass sie zu seinen Lebzeiten noch steht.

47 Plin. nat. 34,26 nennt die Zerstörung der beiden Statuen des Pythagoras und des Alkibiades im Rahmen der Vergrößerung der Curia Hostilia durch Sulla im Jahre 80 v. Chr.: invenio et Pythagorae et Alcibiadi in cornibus comitii positas ... eae stetere, donec Sulla dictator ibi curiam faceret. Hierzu ausführlicher Coarelli (I985) II9-I20 mit Abb. 2I; Coarelli (I993a) 3II-3I2; Sehlmeyer (I999a) 88-89.

48 Wie bei der Statue des Hermodoros erwähnt Plinius auch bei der des Attus Navius, dass sie zu seinen Lebzeiten nicht mehr stand, im Unterschied zu der noch existenten Statue des Horatius Cocles - Plin. nat. 34,2I: namque et Atti Navi statua fuit ante curiam, basis eius conflagravit curia incensa P. Clodii funere. Eine Beschädigung des Sockels erfolgte offensichtlich 52 v. Chr. anlässlich der Verbrennung des Leichnams des Clodius, bei der auch die von Sulla erneuerte Curia zerstört wurde; diese erste Beschädigung scheint aber noch nicht zum Abbau der Statue geführt zu haben, denn auch Dion. Hal. ant. 3,7I,5 berichtet, dass er die Statue noch bei der Curia gesehen habe. Was das endgültige Verschwinden der Statue betrifft, so ist daher die Annahme am plausibelsten, dass die Statue des Attus Navius den darauf folgenden umfangreichen Umbaumaßnahmen durch den Bau der Curia Iulia unter Caesar und Augustus zum Opfer fiel, s. dazu auch Sehlmeyer (I999a) 83-84 mit Anm. 238; Coarelli (I999b) 366.

49 Bei seiner Aufzählung der Gesandtenstatuen erwähnt Plinius nur im Fall der Statue des Cn. Octavius von I62, dass sie zu seinen Lebzeiten in rostris steht (Plin. nat. 34, 23-24) - für die zuvor angesprochenen Statuen der Fidene-Gesandten und der Illyrier-Gesandten fehlt dagegen ein entsprechender Hinweis, so dass man vermuten kann, dass sie nicht mehr standen. Im Fall der Statuen der Fidene-Gesandten wird dies zudem durch die Aussage bei Cic. Phil. 9,4 bestätigt: Lars Tolumnius, rex Veientium, quattuor legatos populi Romani Fidenis interemit, quorum statuae steterunt usque ad meam memoriam in rostris. Cicero hatte sie demnach früher noch gesehen, zum Zeitpunkt seiner Rede waren sie jedoch schon länger nicht mehr existent; hierzu s. auch Sehlmeyer (I999a) 64 und Coarelli (I999a) 212, die ihre Abräumung im Kontext des Bürgerkriegs zwischen Sulla und Cinna bzw. der Bauaktivitäten Sullas bei der Curia und dem Comitium vermuten.

50 Plinius bezeugt, dass zu seiner Zeit die Statue nicht mehr am Forum steht (Plin. nat. 34,23: et ante aedem Castorum fuit Q. Marcii Tremuli equestris togata ...); für das Jahr 43 v. Chr. bezeugt Cicero jedoch noch ihre Existenz (Cic. Phil. 6,I3), dazu Sehlmeyer (I999a) 60. Wahrscheinlich ist es, dass die Reiterstatue spätestens der grundlegenden Restaurierung des Dioskurentempels durch Tiberius zum Opfer fiel, eventuell, je nachdem, wo sie genau stand, auch schon der Neugestaltung des Areals westlich der Regia durch den Bau des Caesartempels und des Augustusbogens.

5I Velleius Paterculus bezeugt die Existenz der 43 v. Chr. für Octavian errichteten Reiterstatue in rostris, wobei er die Situation der augusteischen Rostra meint. (Vell. 2,6I,3: Eum senatus honoratum equestri statua, quae hodieque in 
rostrata des Duilius ${ }^{52}$ (Abb. 8-9), die Statue der Lupa53, die Statue des Horatius Cocles54, die Gesandtenstatue des Cn. Octavius aus dem 2. Jh. 55 sowie die Statue eines Gesandten aus der Zeit des 2. Triumvirats und Parteigängers Octavians, mit Namen Ser. Sulpicius Ru-

rostris posita aetatem eius scriptura indicat, qui honor non alii per trecentos annos quam L. Sullae et Cn. Pompeio et C. Caesari contigerat, pro praetore una cum consulibus designatis Hirtio et Pansa bellum cum Antonio gerere iussit). Die Reiterstatue wurde zunächst bei bzw. auf den unter Caesar 44 v. Chr. neu errichteten Rostra aufgestellt; diese wurde unter Augustus nochmals umgebaut, so dass es gegebenenfalls, je nach konkretem Standort der Reiterstatue, zu einer Versetzung der Statue des Octavian kam; das Zeugnis des Velleius bezieht sich in jedem Fall auf die Situation der augusteischen Rostra. Was für die Reiterstatue des Octavian gilt, ist ebenfalls für die Reiterstatuen des Sulla, Pompeius und Caesar anzunehmen (auch wenn die Quellen nicht explizit ihre Existenz in der Kaiserzeit bezeugen): Nach Cass. Dio 43,49,I-2 ließ Caesar die Reiterstatuen des Sulla und des Pompeius, die 48 v. Chr. von ihrem Standort in rostris entfernt worden waren (Cass. Dio 42,I8,2), an seiner 44 v. Chr. neu errichteten Rostra wieder anbringen; ebenso wurde dort die bei Vell. 2,6I,3 bezeugte Reiterstatue des Caesar aufgestellt. Sollte der Umbau der caesarischen Rostra unter Augustus den Standort dieser Reiterstatuen beeinträchtigt haben, so ist wohl von ihrer Umsetzung auf die augusteische Rostra auszugehen - eine Entfernung erscheint mir im historischen Kontext weniger wahrscheinlich und hätte wohl zudem Niederschlag in der literarischen Überlieferung gefunden. Informationen über das weitere Schicksal der Reiterstatuen am kaiserzeitlichen Forum fehlen; angesichts der wiederholten Umbaumaßnahmen an der Rostra in der folgenden Kaiserzeit des I.-3. Jh. n. Chr. ist jedoch zu vermuten, dass die Reiterstatuen irgendwann ihren prominenten Standort an Ehrenstatuen der Kaiser abtreten mussten. - Ausführlicher zu der Umsetzung der Reiterstatuen des Sulla und Pompeius und der Aufstellung der Reiterstatuen von Caesar und Octavian Sehlmeyer (I999a) 23I-232, 249; Sehlmeyer (I999a) 205 Anm. 5 erwägt unter (schwachem) Verweis auf App. BC I,45I-452, dass die Reiterstatue des Sulla in der Kaiserzeit entfernt wurde. Zum Umbau der caesarischen Rostra unter Augustus: Verduchi (I999) 2I4-2I5 mit weiterer Literatur. 52 Ihr Fortbestehen bezeugen Plin. nat. 34,20 (... columnarum ... item C. Duillio ..., quae est etiam nunc in foro ...) und Quint. I,7,I2 (... uta Latinis veteribus d plurimis in verbis adiectam ultimam, quod manifestum est etiam ex columna rostrata, quae est Duilio in foro posita). Dabei scheint es wohl in augusteischer Zeit zu einer Restaurierung zumindest des Säulensockels gekommen sein, dazu s.u. Anm. 63.

53 Für den Fortbestand der Lupa lässt sich nur indirekt argumentieren, unter Verweis auf den Fortbestand der Ficus Ruminalis, bei der die Statue aufgestellt war und mit der zusammen sie fortan eine symbolträchtige Einheit am Comitium bildete. Liv. Io,23,I2 bezeugt für das 3. Jh. v. Chr. die Aufstellung der Statue bei der Ficus Ruminalis (Eodem anno Cn. Et Q. Ogulnii aediles curules aliquot feneratoribus diem dixerunt; quorum bonis multatis ex eo quod in publicum redactum ... ad ficum Ruminalem simulacra infantium conditorum urbis sub uberibus lupae posuerunt). Die in späteren Quellen (s.u.) bezeugte Fürsorge um den Bestand der Ficus Ruminalis wird man auch auf die dort aufgestellte Statue der Lupa übertragen müssen, definierte diese doch rückwirkend die Bedeutung der Ficus. Wäre die Statue hingegen abgeräumt worden, hätte dieser ideologisch nicht gering zu bewertende Eingriff sicherlich Niederschlag in den Quellen gefunden. - Den Bestand der Ficus Ruminalis mindestens bis zum Jahr 58 n. Chr. bezeugt Tac. ann. 13,58: Eodem anno Ruminalem arborem in comitio, quae octingentos et triginta ante annos Remi Romulique infantiam texerat, mortuis ramalibus et arescente trunco deminutam prodigii loco habitum est, donec in novos fetus revivisceret. Für die Lebzeit des Plinius ist sie bezeugt bei Plin. nat. 15,77-78: Colitur ficus arbor in foro ipso ac comitio Romae nata, sacra fulguribus ibi conditis magisque ob memoriam eius quae, nutrix Romuli ac Remi, conditores imperii in Lupercali prima protexit, ruminalis appellata, quoniam sub ea inventa est lupa infantibus praebens rumim, (ita vocabant mammam), miraculo ex aere iuxta dicato, tamquam in comitium sponte transisset Atto Navio augurante. Nec sine praesagio aliquo arescit rursusque cura sacerdotum seritur. Die Formulierung, miraculo ex aere‘ wird bei Coarelli (I985) 33, 88-9I und Coarelli (I995) überzeugend mit der betreffenden Statue der Lupa und den Zwillingen identifiziert. 54 Ihre Existenz noch zu Lebzeiten des Plinius bezeugt Plin. nat. 34,2I: alia causa, alia auctoritas M. Horatii Coclitis statuae, quae durat hodieque, cum hostes a ponte sublicio solus arcuisset.

55 Die Formulierung bei Plin. nat. 34,24 legt ihre Existenz noch zu Lebzeiten des Plinius nahe: in qua legatione interfecto senatus statuam poni iussit quam oculatissimo loco, eaque est in rostris; - Cic. Phil. 9,4 bezeugt ferner für das Jahr 43 v. Chr. ihre Existenz: Cn. Octavi ... statuam videmus in rostris. Hierzu Sehlmeyer (I999a) 66, jedoch nur mit Bezug auf die Existenz bis 43 v. Chr. 


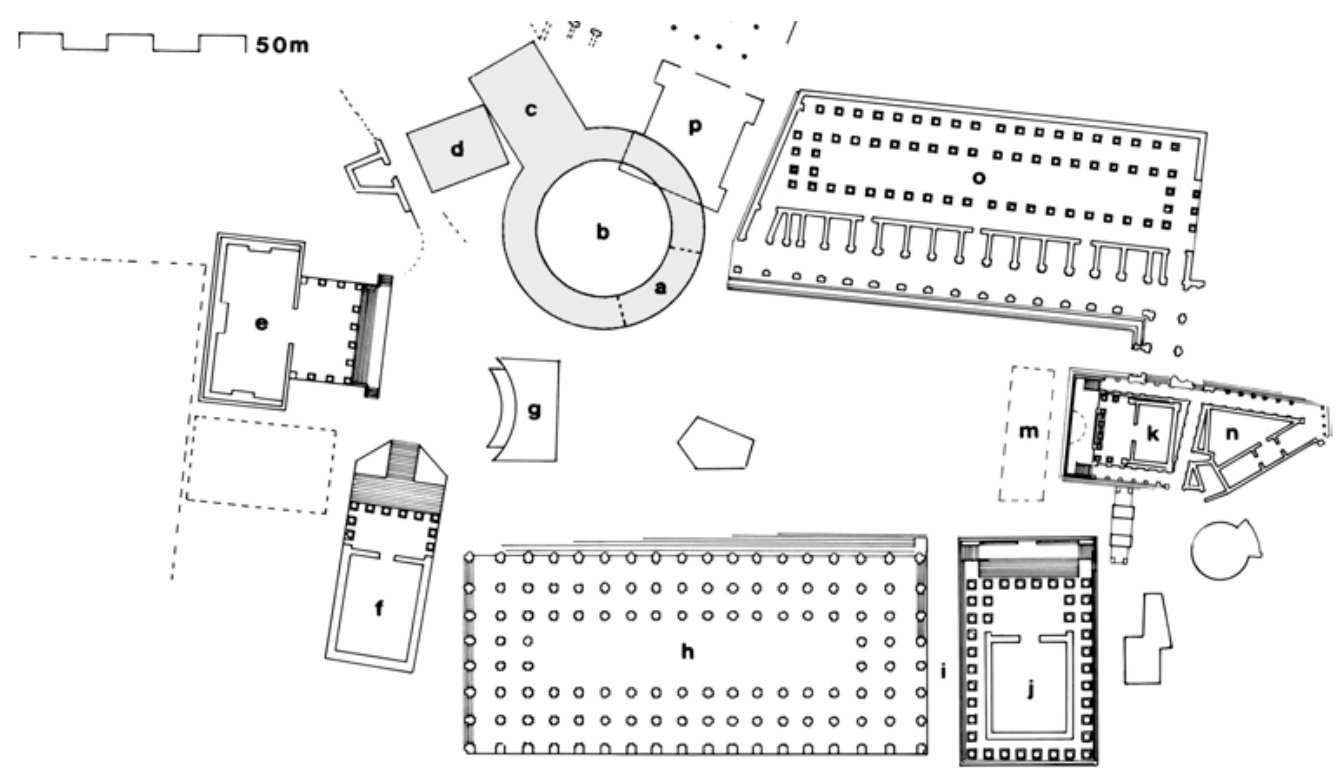

Abb. ${ }_{13}$ | Plan des Forum Romanum mit den Veränderungen im Bereich des Comitiums unter Sulla, Caesar und Augustus (a-b: republikanisches Comitium mit rostra; c: republikanische Curia Hostilia bzw. Cornelia; g: caesarisch-augusteische Rostra, p: Curia Iulia)

fus $^{56}$. Die Wende von der Republik zur Kaiserzeit lässt also eindeutig eine Reduktion im Bestand der Monumente erkennen, erweist sich gewissermaßen als Bermudadreieck für eine Reihe der alten Monumente des republikanischen Forums. ${ }^{77}$

Man könnte versucht sein, das Verschwinden der Monumente bzw. ihre Ausdünnung damit zu erklären, dass es unter Sulla sowie dann nochmals unter Caesar und Augustus zu nachhaltigen Umbauten beim Comitium und bei der Curia kam, die die Landschaft des ehemaligen politischen Zentrums grundlegend veränderten (Abb. 13 )..$^{8}$ Damals wurde das

56 Cic. Phil. 9,I3 ff. wirbt im Jahr 43 v. Chr. für die Errichtung der Statue in rostris; dass er damit Erfolg hatte und dass diese Statue auch noch im 2. Jh. n. Chr. existierte, wird durch Dig. I,2,2,43 bezeugt: hic cum in legatione perisset, statuam ei populus romanus pro rostris posuit, et hodieque exstat pro rostris augusti. Hierzu s. Sehlmeyer (I999a) 252-253, der jedoch fälschlicherweise eine sekundäre Verlagerung der Statue von der Rostra an der Westseite des Forums zu der vor dem Caesartempel an der Ostseite annimmt.

57 Unklar ist die Situation bei der Statue des Mucius Scaevola, bei der jedoch auch ihre grundsätzliche Existenz nicht klar ist, s. Sehlmeyer (I999a) 96-97. Unklarheit wie auch Zweifel gelten ebenso im Fall der Statue des Porsenna, s. Sehlmeyer (I999a) IOI-IO2. Das Gleiche trifft auch für die Statuen des Titus Tatius und des Romulus zu, die man eher als spätere kaiserzeitliche Statuenaufstellungen verstehen möchte, s. Sehlmeyer (I999a) 74-76, 8I. $58 \mathrm{Zu}$ den baulichen Eingriffen im nordwestlichen Forumsareal in comitio unter Sulla sowie unter Caesar und Augustus übergreifend: Zanker (I972) 7-I2, 40-43; Coarelli (I985) 233-257; Zanker (I987) 34, 85-87; Patterson (I992) I92-I94; Wallace-Hadrill (I993) 55; Gros u. Torelli (I994) I2O-I2I, I24-I25, I69-I70; Kolb (I995) 252, 254, 262-264, 357; Favro (I996) 37, I96-200; Carafa (I998) I56-I59; Knell (2004) 28-3I, 38-4I; Hölscher (2006a) IIO-III, II5; Haselberger (2007) 57, 73-77; Freyberger (2009a) 54-56. 
Comitium als politische Versammlungsstätte aufgegeben und ausradiert und wurde die Rednertribüne hinüber auf die Westseite der freien Forumsfläche verlagert (Abb. I3: $\mathrm{a}-\mathrm{b}, \mathrm{g})$;9 ebenso wurde die Curia mehrmals umgebaut, vergrößert, verlagert und neu orientiert (Abb. I3: c, p) ${ }^{60}$ Für Statuen und Monumente, die im Bereich dieser Baustelle lagen (Abb. 6), bedeuteten diese Umbauten natürlich, dass sie in ihrem Aufstellungsort problematisch, eventuell gar obsolet wurden. So wird etwa bei Plinius das Schicksal der Statuen des Pythagoras und des Alkibiades damit erklärt, dass durch die Vergrößerung der Curia Cornelia unter Sulla beide Statuen, die bis dahin dicht neben der alten Curia Hostilia gestanden hatten, verschwanden (Abb. 6: Nr. 7-8). ${ }^{6 r}$ Und entsprechend kann man das Verschwinden anderer Statuen und Monumente dann mit der Verlagerung der Rostra sowie des nochmaligen Neubaus der Curia Iulia unter Caesar sowie Augustus erklären. ${ }^{62}$

Doch wie glaubhaft ist dieser Erklärungsansatz eigentlich? Gemeinhin bedeuten in der Antike Bauaktivitäten und Umbauten keineswegs selbstverständlich, dass Statuen und Monumente, die in einem bestimmten Bereich stehen, einfach beschädigt und zerstört werden, bzw. abgeräumt werden und für immer verschwinden. Vielmehr werden Statuen und Monumente versetzt, bzw. falls sie beschädigt waren, können sie restauriert oder durch neue ersetzt werden. Etwas Derartiges scheint bei der Columna rostrata des Duilius (Abb. 8-9) erfolgt zu sein, jedenfalls wird der überlieferte Säulensockel aufgrund seines Materials und des Duktus seiner Inschrift gemeinhin auf eine augusteische Erneuerung zurückgeführt. ${ }^{6} 3$ Bei einer anderen Statue, die schon weiter östlich auf der Via sacra nahe dem Titusbogen stand, der ominösen Reiterstatue der Cloelia bzw. Valeria, erfahren wir in den literarischen Quellen, dass diese Statue im späteren I. Jahrhundert v. Chr. durch Brand zerstört und später wieder neu errichtet wurde. ${ }^{64}$ Und umgekehrt erfahren wir im Fall von

59 Zur Zerstörung des Comitiums und der Verlagerung der Rostra: Coarelli (1983) I35-I36; Coarelli (I985) 237-257; Coarelli (I993a) 3I2-3I4; Kolb (I995) 254, 262-263; Carafa (I998) I48-I55, I56-I59; Coarelli (I999a) 2I3; Coarelli (I999C) 296; Verduchi (I999) 2I4-2I5; Haselberger (2002) 2I6; Knell (2004) 28-3I; Haselberger (2007) 75 mit Anm. 9I.

60 Zum Bau der Curia Cornelia sowie, nach deren Zerstörung, zu dem der Curia Iulia: Coarelli (I985) 234-237; Coarelli (I993b); Tortorici (I993) 332-333; Haselberger (2002) 99; Knell (2004) 28, 3I, 38-4I.

6I Plin. nat. 34,26: invenio et Pythagorae et Alcibiadi in cornibus comitii positas ... eae stetere, donec Sulla dictator ibi curiam faceret. Ausführlicher hierzu Coarelli (I985) II9-I20 mit Abb. 2I; Coarelli (I993a) 3II-3I2; Sehlmeyer (1999a) 88-89.

62 So etwa im Fall der Statue des Attus Navius, deren Existenz nach 52 v. Chr. durch Plin. nat. 34, 2I und Dion. Hal. ant. 3,71, 5 bezeugt ist; hierzu ausführlicher s.o. Anm. 48.

63 Chioffi (I993); Jordan-Ruwe (I995) 58-59; Sehlmeyer (I999a) II7-II8; Kondratieff (2004) IO-I4; Schmuhl (2008) 86-87; Roller (2009) 222. Unklar bleibt, in welchem Umfang die Erneuerung erfolgte: Betraf sie nur den Säulensockel (so Jordan-Ruwe a.a.O.), oder auch weitergehend die ganze Säule, bzw. kam es damals vielleicht sogar zu einer Versetzung der Säule hinüber zur caesarisch-augusteischen Rostra, im Rahmen der weitergehenden Eingriffe in die Topographie der Westseite des Forums (dass derartige Columnae rostratae durchaus versetzt werden konnten, zeigt das Schicksal der vier augusteischen Columnae rostratae vom Forum hoch zum Capitol, s. Palombi [1993a] 324-329, Ders. [1993b])?

64 Während Dion. Hal. ant. 5,35,2 berichtet, dass die Statue zu seiner Zeit nicht mehr stehe, da sie durch Brand vernichtet worden sei, bezeugen Sen. dial. 6,16,3 und Serv. Aen. 8,646, dass die Statue zu ihrer Lebzeit steht, woraus zu schließen ist, dass die Statue wieder errichtet wurde. Ausführlicher zur Reiterstatue der Cloelia bzw. 
Statuen, die man nicht mehr wünschte, dass man sie gezielt abräumte und in Werkstätten zum Einschmelzen brachte, wie etwa bei manchen Statuen Caesars während der Unruhen nach den Iden des März 44, oder den Statuen des Lepidus und des Marcus Antonius bei den Rostren. ${ }^{65}$ Aber schließlich konnten abgeräumte Statuen offensichtlich auch aufbewahrt und später wieder errichtet werden, wie es das Schicksal der Reiterstatuen des Sulla und Pompeius illustriert, die nach der Schlacht von Pharsalos 49 v. Chr. von den Rostren entfernt und im Jahr 44 v. Chr. bei der Einweihung der neuen Rostra durch Caesar wieder aufgestellt wurden. ${ }^{66}$ Kurzum: Statuen und Monumente verschwinden nicht einfach und klanglos, und schon gar nicht aus einem so prominenten urbanen Raum wie dem Forum. Sie verschwinden nur, wenn man will, dass sie verschwinden, bzw. wenn man kein Interesse daran hat, dass sie weiterhin stehen. ${ }^{67}$

Umgekehrt mag man bei manchen der Monumente, die auf dem augusteischen Forum bestehen bleiben, durchaus ein konkreteres Interesse an ihrem Fortbestehen rekonstruieren: Die Gesandtenstatue des Sulpicius ehrte einen Parteigänger Octavians und Geg-

Valeria: Hölscher (I978) 332, 334-335; Bergemann (I990) I57; Sehlmeyer (I999a) 98-Ior; Hölscher (200I) I97 mit Anm. 39.

65 Zerstörung von Statuen Caesars: App. B.C. 3,8-9; hierzu: Sehlmeyer (I999a) 237-238. - Zerstörung der Reiterstatue des M. Aemilius Lepidus: Cic. ad Brut. I,I5,9, Cass. Dio 46,5I,4; hierzu: Sehlmeyer (I999a) 248-249, 254. - Zerstörung der Quadriga des M. Antonius im Rahmen seiner Damnatio memoriae: Plut. Anton. 86,9, Cass. Dio 5I,I9,3; hierzu: Sehlmeyer (1999a) 25I mit Anm. 260. - Weiterhin bekannte Beispiele eines aggressiven Denkmälerkrieges sind die wechselseitigen Zerstörungen von Ehrenmonumenten unter Marius und Sulla: Hölscher (1980); Sehlmeyer (1999a) I96-I97, 2I7-2I8; Stein-Hölkeskamp (im Druck), dort die Ausradierung der Erinnerung an einen Politiker als neue Qualität in der Selbstdarstellung der Nobiles im Stadtbild betont. Weniger bekannte Fälle der politisch motivierten Statuenzerstörung sind für Ehrenstatuen des M. Marius Gratidianus (80 v. Chr.) und des P. Clodius (44/43 v. Chr.) überliefert, dazu Sehlmeyer (I999a) I99-20I, 209, 2I6-2I7. Generell zum ,aggressiven‘ Potential, das Denkmäler gewinnen konnten, und zum Kampf um Denkmäler s. auch Hölscher (200I) 207-209.

66 Entfernung und Wiederaufstellung der Reiterstatuen Sullas und Pompeius' in rostris: Cass. Dio 42,I8,2; 43,49,I-2, Plut. Caes. 57,6; hierzu: Sehlmeyer (1999a) 23I-232. - Ähnlich ist auch der Fall bei den zerstörten Monumenten des Marius und des Sulla: auch sie werden unter veränderten politischen Konstellationen, nach der siegreichen Rückkehr des Sulla von ihm oder seinen Anhängern bzw. nach dessen Tod durch Caesar wiedererrichtet: Hölscher (I980) 356-357, 368-369; Sehlmeyer (I999a) 2I7-2I8; Hölscher (200I) 208.

67 Dass Beschädigungen von Monumenten dabei wahrlich keinen Hindernisgrund darstellen, zeigen die wiedererrichteten Monumente des Marius und wohl auch Sullas (s.o. Anm. 66), bei denen es sich jeweils um reparierte bzw. neu geschaffene Ersatzmonumente gehandelt haben wird. Entsprechend hätten Statuen aus dem Bereich des alten Comitiums, falls sie im Rahmen der umfangreichen Bauarbeiten zu Schaden gekommen waren, wieder neu errichtet werden können. Gerade im Fall der Rostra erscheint dies in besonderem Maße naheliegend: Denn die dort aufgestellten Statuen bildeten ein zentrales Element im traditionellen Erscheinungsbild der Rostra. Und so, wie man anfangs das Erscheinungsbild der alten Rostra mit ihrer gebogenen Form getreu bei der caesarischen Neuerrichtung auf der Westseite des Forums zu wahren suchte, obgleich es für die neue Raumsituation eher kontraproduktiv war und daher auch bei der augusteischen Neugestaltung korrigiert wurde, hätte man auch leicht die berühmten Statuen und Memorialmonumente, welche ebenfalls für das traditionelle Erscheinungsbild der alten Stätte der politischen Entscheidungsfindung konstitutiv waren, umsetzen und bei der neuen Rostra wieder errichten lassen können. Dass dies jedoch offensichtlich zu großen Teilen nicht geschah, wird man kaum anders als einen bewussten Akt der Entscheidung gegen diese Monumente deuten können. 
Abb. 14 | Darstellung einer Columna rostrata des Octavian, Denar 29-27 v. Chr.

ner des Antonius ${ }^{68}$; die Gesandtenstatue des Octavius aus dem 2. Jh. ehrte einen Angehörigen der sich sonst politisch eher wenig hervortuenden Gens des Octavian ${ }^{6}$; die Columna rostrata des Duilius (Abb. 8-9) mochte wiederum als Vergleichspunkt für die Columnae rostratae des Octavian nach Naulochos und Actium hilfreich sein (Abb. I4), indem sie (ähnlich wie die Bezugnahme der rostra von Actium auf diejenigen von Antium ${ }^{70}$ ) bewirkte, dass die Siege im Bürgerkrieg eine andere historische Uminterpretation erfuhren, welche ihre politische Brisanz mit zu kaschieren half. ${ }^{\mathrm{I}}$

Alles in allem scheint also für die wenigen Monumente, die überdauerten, ein spezifisches Interesse ausschlaggebend gewesen $\mathrm{zu}$ sein, dass sie bestehen blieben. Was aber die große Zahl der Monumente betrifft, die als Gesamtkonzept das traditionelle Erscheinungsbild um das Comitium seit Jahrhunderten geprägt und seit Jahrhunderten den politischen Raum orchestriert hatten mit ihrer Präsentmachung der glorreichen Vergangenheit Roms und seiner herausragenden Vertreter vor allem der Republik: An ihnen scheint damals offensichtlich kein grundlegendes Interesse mehr bestanden zu haben. Anders ist ihr Verschwinden an der Wende von der Republik zur Kaiserzeit schwer zu erklären.

\section{Rom unter Augustus: Ein neuer, kontrollierter Zugriff auf die Vergangenheit}

Dass hier ein strukturelles Phänomen der frühen Kaiserzeit dahinter steht - oder allgemeiner formuliert: ein Phänomen, das sich konsequent aus der Umwandlung der aristokratisch geprägten Stadt des republikanischen Roms hinüber in eine nun monarchisch funk-

68 Hierzu s. Sehlmeyer (I999a) 252-253.

69 Ebenso Sehlmeyer (1999a) 66.

70 rostra von Actium an den Rostra aedis Divi Iulii und ihr Bezug zu den rostra von Antium an der Rostra Augusti: Zanker (1972) I3-I4; Coarelli (I985) 308-324; Zanker (I987) 86-87; Jordan-Ruwe (I995) 66; Gros (I996); Haselberger (2002) I03; Knell (2004) 37-38; Haselberger (2007) 75; Schmuhl (2008) 152, 213; Freyberger (2009) 6I.

7I Columnae rostratae des Octavian: Welin (I953) I56, I73; Coarelli (I985) 259; Zanker (I987) 50, 86-87; Palombi (I993a); Palombi (I993b); Jordan-Ruwe (I995) 64-66; Sehlmeyer (I999a) 255-257; Sehlmeyer (2002); Haselberger (2007) 59 mit Anm. 69, 77 mit Anm. 93; Schmuhl (2008) I43-I45, I49-I50, 213. 
tionierende Stadt der Kaiserzeit einstellte, und dass wir somit hier beim Forum ein strukturelles Phänomen im augusteischen Umgang mit Monumenten im öffentlichen Raum vor uns haben, legt ein Parallelbefund nahe: die Situation auf dem Capitol. In der Republik waren hier, ebenfalls ab dem mittleren 4. Jahrhundert, zahlreiche Memorialstatuen errichtet worden. Vor allem die Triumphatoren wurden hier mit Ehrenstatuen ausgezeichnet - das Capitol scheint sogar das Forum mit dem Comitium noch überrundet zu haben, was die Dichte und Attraktivität der Statuenehrungen und Monumente betraf.72 Ähnlich wie auf dem republikanischen Forum hielten diese Monumente somit die Geschichte des glorreichen Roms nahsichtig und eindrucksvoll vor Augen. Und ähnlich wie beim Forum kommt es auch hier an der Wende von der Republik zur Kaiserzeit zur Ausradierung dieser visuell präsent gehaltenen Geschichte der Vergangenheit. So berichtet uns Sueton, dass die Statuen der viri illustres auf dem Capitol unter Augustus, angeblich wegen der Enge, abgeräumt und auf das Marsfeld verlagert wurden, wo sie dann unter Caligula zu Schaden kamen.73

Dieser Parallelbefund erscheint mir aufschlussreich. Forum bzw. Comitium und Capitol waren im republikanischen Rom die beiden zentralen öffentlichen Räume, die als Bühne der politischen Repräsentation besondere Attraktivität genossen und entsprechend zum ersten Ort rühmender Monumente und Ehrenstatuen wurden: Die in ihnen visualisierte Vergangenheit stellte den nachfolgenden Generationen die exempla politischen und militärischen Handelns vor Augen - und die identitätsstiftende Kraft der beschworenen Vergangenheit wirkte nachhaltig in das diskursive Klima dieser öffentlichen Räume hinein, als Vergleichspunkt und Herausforderung für die Gegenwart. Genau diese Wirkungskraft einer beschworenen Vergangenheit scheint es dann aber zu sein, die diesen Statuenwäldern dann am Übergang in die Kaiserzeit (oder vorsichtiger gesagt: beim Aufkommen monarchischer Machtstrukturen) zum Verhängnis wird. Offensichtlich wird hier die aufdringliche Vergegenwärtigung der Vergangenheit nicht mehr gewünscht - und werden die öffentlichen Räume von dem allzu starken Ballast der Vergangenheit gereinigt, um der Gegenwart um so mehr Platz für einen wirkungsvolleren und konkurrenzlosen Auftritt zu verschaffen.

72 Zur Aufstellung von Ehrenstatuen auf dem Capitol: Lahusen (I983) 7-I2; Reusser (I993) 46-48, 209-213; Sehlmeyer (I999) 67-82, II2-I3I, I59-I6I, I9I-I97, 222-224, 229-230; Hölscher (200I) I96-I97; Hölkeskamp (2004) I42-I47, I5I-I58, I62; Schmuhl (2008) 73-I42 passim, 249-250. - Bezeichnenderweise kam es im Jahre I79 am Capitol ebenfalls zu einer von den Censoren initiierten Räumung von Weihgeschenken und Beutestücken, bei der wohl Ehrenstatuen aber zumindest nicht zentral betroffen waren, dazu Reusser (I993) 46; Sehlmeyer (I999a) I59-I6I; Walter (2004) i60 mit Anm. II9.

73 Suet. Cal. 34,I: statuas virorum inlustrium ab Augusto ex Capitolina area propter angustias in campum Martium conlatas ita subvertit atque disiecit ut restitui salvis titulis non potuerint ...; hierzu vor allem Lahusen (I983) IO-II; Reusser (I993) 50-5I mit Anm. II9 (Einschränkung der betroffenen Statuen); Favro (I996) 20I (dabei mehr die sorgfältige Wiedererrichtung auf dem Marsfeld als den Tatbestand der Abräumung akzentuierend); Sehlmeyer (I999a) 270-27I. - Überraschenderweise wird diese Aktion in den Diskussionen um die Umgestaltung Roms unter Augustus nur selten in den Blick genommen. 


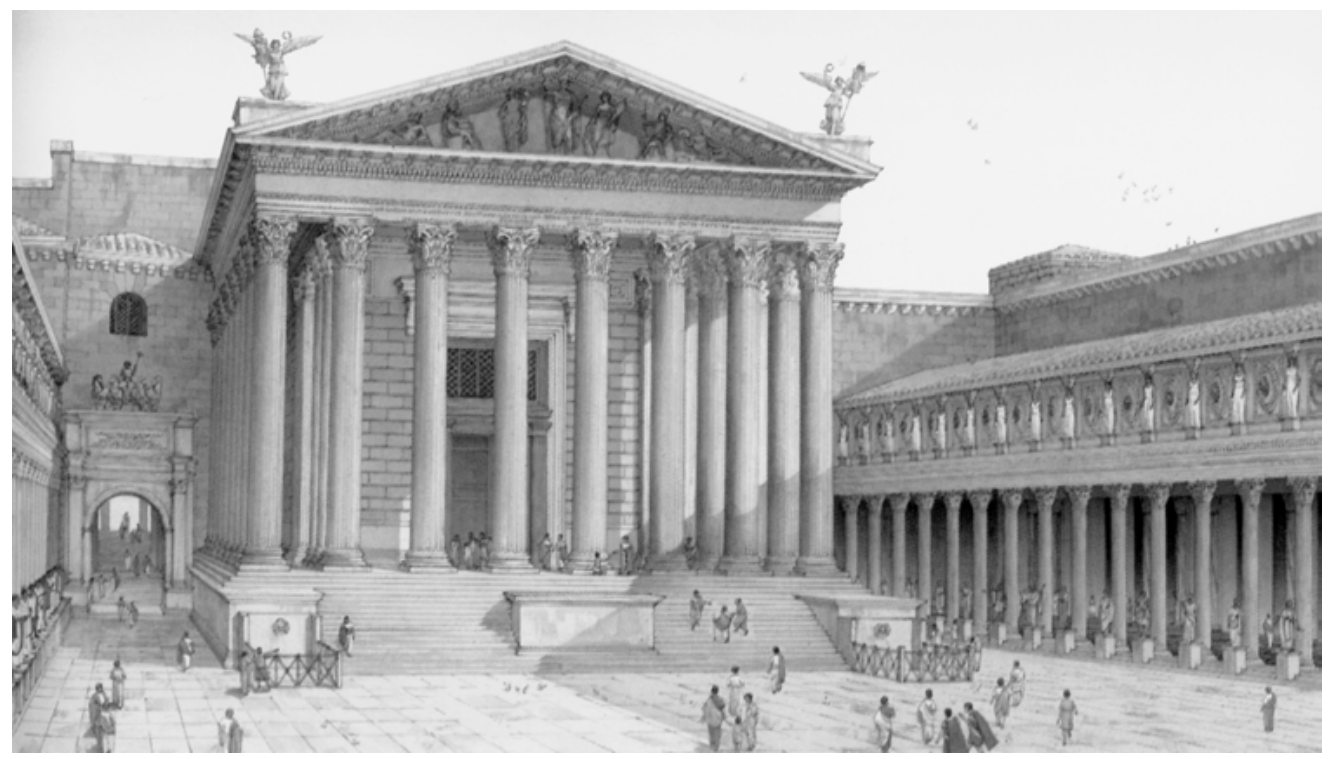

Abb. 15 | Rekonstruktion des Augustusforums

Dieser Umgang mit der glorreichen Vergangenheit am Forum und am Capitol mag nun um so mehr überraschen, wenn wir den konträren Umgang mit der Vergangenheit am Augustusforum bedenken - oder sollten wir vielleicht besser sagen: den scheinbar konträren Umgang dort (Abb. I5-I7)?74 In den seitlichen Portiken sowie Exedren des Augustusforums und, wie neuere Untersuchungen zeigen, auch im Bereich vor den Säulenstellungen der Portiken standen bekanntlich Reihen von Statuen berühmten Personen der römischen Geschichte, die summi viri, von den Anfängen der Stadt bis in die jüngste Vergangenheit, auf der einen Seite die Iulier, auf der anderen die Römer.75 Was auf dem Capitol und dem Forum an Dialog mit der Vergangenheit abgebrochen worden war, das wurde hier an Dialog um so nachhaltiger gesucht: Hier war die Erinnerung und die Vergegenwärtigung der glorreichen Vergangenheit offensichtlich unverzichtbares Element bei der Evo-

74 Grundlegend zum Augustusforum: Zanker (I968); Wallace-Hadrill (I993) 56-58; Favro (I996) I26-I28, I75-I76, 200, 230-23I; Zanker (I987) II8-II9, I96-I98, 2I3-2I7; Ganzert - Kockel (I988); Kockel (I995); Spannagel (I999); La Rocca (200I) I84-I95; Haselberger (2002) I30-I3I; Knell (2004) 72-83; Walter (2004) 4I7-422; Gowing (2005) I38-I45; Haselberger (2007) I57-I6I, I97-I99; Meneghini - Santangeli Valenzani (2007) 43-60; Ungaro (2007) II8-I69; s. auch die Ausführungen von U. Schmitzer zum Augustusforum hier in diesem Band.

75 Hierzu ausführlich: Zanker (I968) I4-I8; Lahusen (I983) 23-26; Zanker (I987) 204-206, 213-2I7; Luce (I990); Wallace-Hadrill (I993) 56-57; Spannagel (I999) 86-255, 256-358; Itgenshorst (2004) 452-458; Walter (2004) 4I7-422; Gowing (2005) I38-I45; Itgenshorst (2005) 9-II, 223-226; Meneghini - Santangeli Valenzani (2007) 55-58; Ungaro (2007) I20-I22, I26, I59-I69; Geiger (2008); s. auch Schmitzer in diesem Band 8I-83. Neue Rekonstruktion von Statuenaufstellung auch vor den Säulen der Porticus: Meneghini - Santangeli Valenzani (2007) 56 Abb. 48, 57; Ungaro (2007) I26 und Abb. I44-I45. 


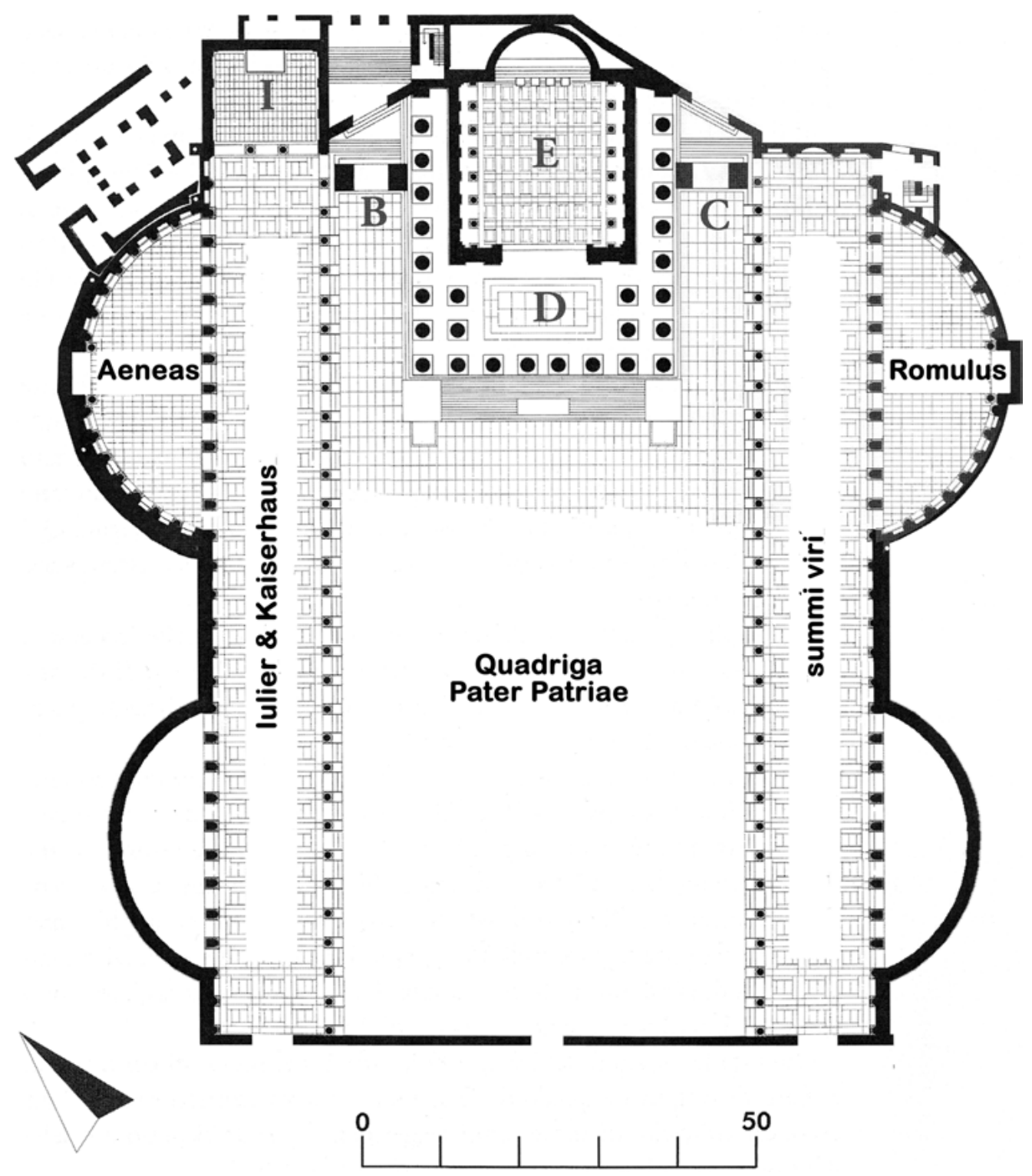

Abb. 16 | Plan des Augustusforums mit Rekonstruktion des Statuenprogramms 


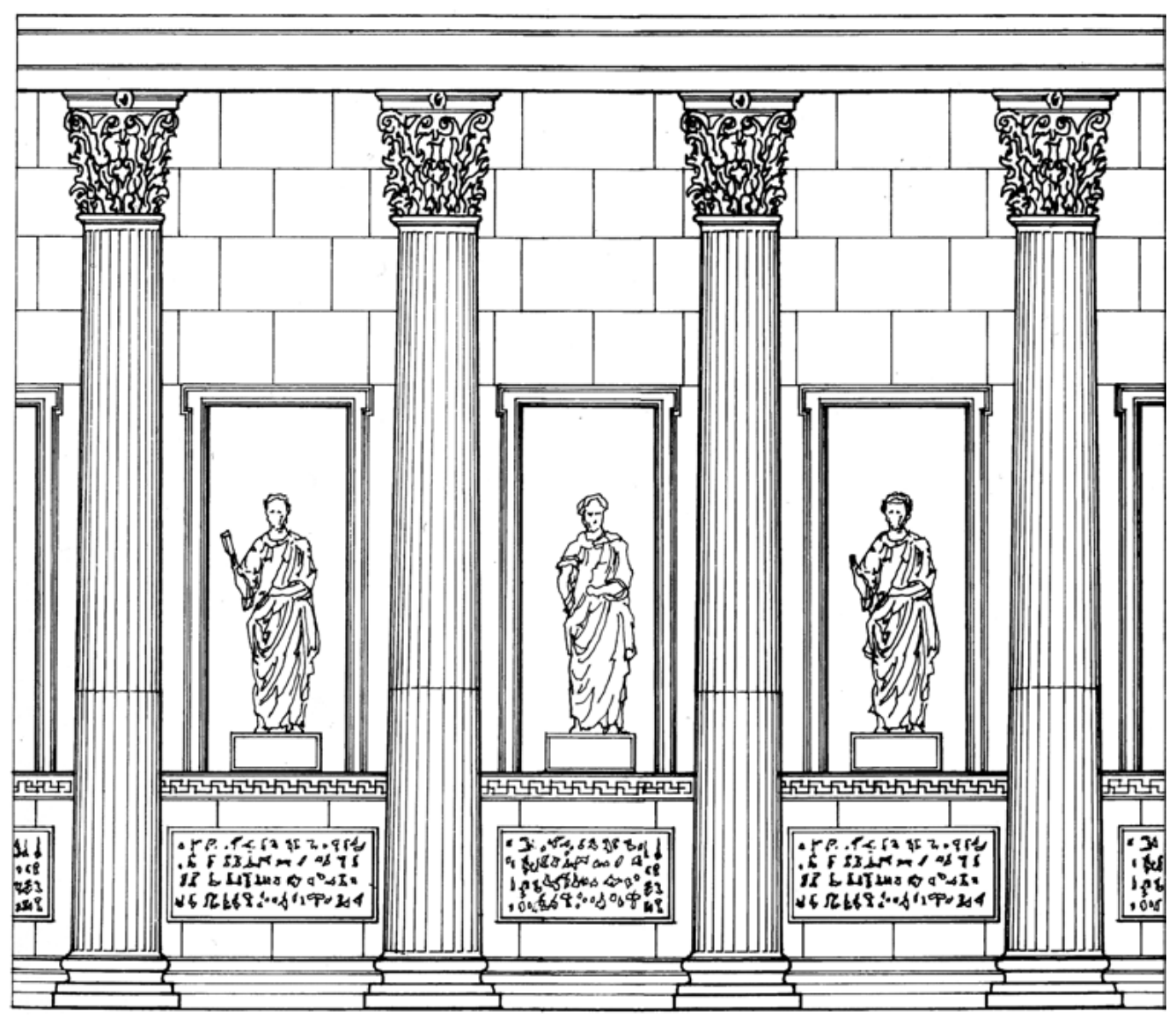

Abb. 17| Rekonstruktion der Statuenaufstellung der summi viri in der Porticus des Augustusforums

zierung eines diskursiven Klimas, das diesen Raum der öffentlich-politischen Kommunikation eindeutig anreichern sollte.

Eine ähnliche Situation lässt sich, im Medium des Textes, auch in den berühmten Fasti consulares und Fasti triumphales beobachten, die am Augustusbogen am Forum angebracht waren (Abb. I8): $7^{6}$ Auch dort tauchen all die Namen der historischen Persönlichkeiten auf,

76 Auf die umfangreiche und kontroverse Diskussion, an welchem der literarisch für das Forum überlieferten Augustusbögen (,Actiumbogen“ vs. ,Partherbogen') die Fasti angebracht waren und wo dieser stand, braucht in diesem Zusammenhang nicht weiter eingegangen zu werden. - $\mathrm{Zu}$ den Fasti und ihrem Anbringungsort: Degrassi (I945-46); Gatti (I945-46); Zanker (I972) I5-I6; Coarelli (I985) 258-308; Nedergaard (I988); Nedergaard (I993); Wallace-Hadrill (I993) 52-53; Simpson (I993); Nedergaard (I994/95); Spannagel (I999) 245-250; Haselberger (2002) 5I-52; Itgenshorst (2004) 437-439, 443-452; Itgenshorst (2005) IO-I2, 219-223; Haselberger (2007) I47 mit Anm. I88; Freyberger (2009) 62-70, bes. 64-67. 


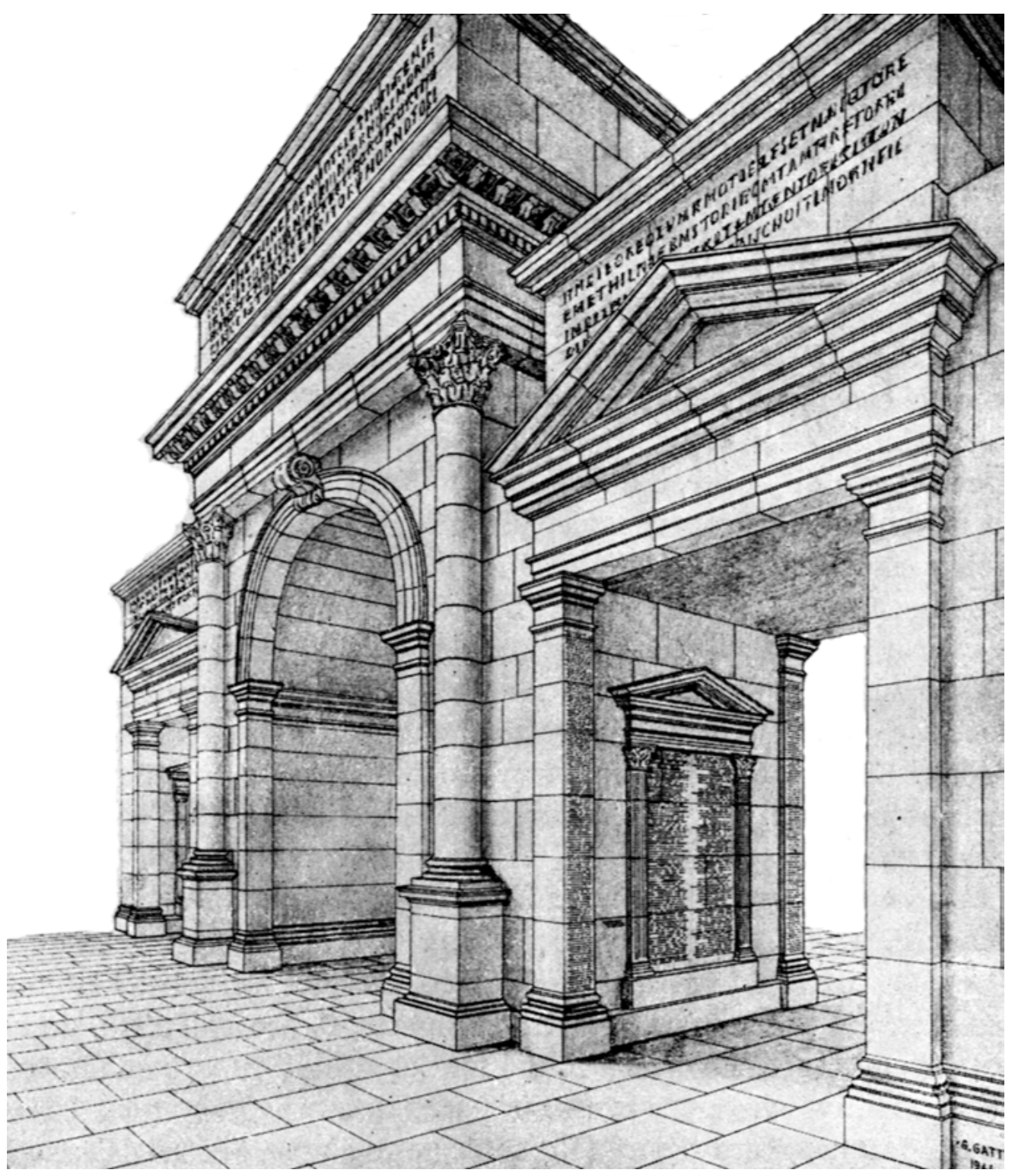

Abb. 18| Rekonstruktionsvorschlag des Augustusbogens mit den Fasti nach G. Gatti 
deren Statuen wir gleichzeitig auf dem Capitol und dem Forum verschwinden sehen. Und schließlich traten diese Personen der Vergangenheit, gewissermaßen als Verlebendigung ihrer Statuen vom Augustusforum, in der ephemeren Inszenierung der Pompa funebris für Augustus im Jahr I4 n. Chr. wieder auf, indem ihre Totenmasken in den Reihen der Ahnen des verstorbenen Princeps mitgetragen wurden.77

Was jedoch das Augustusforum, die Fasti sowie die Pompa funebris des Augustus in ihrem jeweiligen Umgang mit der Vergangenheit deutlich von dem der Statuen auf dem Capitol und dem Forum unterscheidet, ist, dass hier eine andere Form der Erinnerung an die Vergangenheit praktiziert wird: Die Vergangenheit wird hier nun in kontrollierte Bahnen gebracht, ihre Vergegenwärtigung erfolgt immer mit der klaren Zielrichtung, lediglich ein Vorspiel für die um so glorreichere Gegenwart und Herrschaft des Augustus zu sein. ${ }^{8}$ Die Statuen der summi viri auf dem Augustusforum flankieren, orchestrieren gar die große Statue des Augustus in der Quadriga, die das Augustusforum in der Mitte des Platzes dominierte, als Zielpunkt aller statuarischen Ausstattung (Abb. I6).79 Eine entsprechende hierarchische Ausrichtung zeigen ebenfalls die im Leichenzug des Augustus mitgetragenen Ahnenmasken. Und auch die Fasti münden mit ihren Listen immer zielgerade in der Gegenwart und in der Figur des Augustus, als der Erfüllung der in der Vergangenheit angelegten Geschichte Roms.

Das heißt: Dort, wo Strukturen gefunden werden konnten, um den Dialog mit der Vergangenheit kontrolliert unter Bezug und mit Ausrichtung auf die Gegenwart zu inszenieren, da konnte auch im öffentlichen Raum des augusteischen bzw. monarchisch regierten Roms die Vergangenheit als Gegenüber zur Gegenwart präsent gemacht werden. Dort aber, wo eine derartige Kontrolle und Lenkung der Erinnerung schwieriger zu realisieren war, wo die Präsenz der Vergangenheit mit der der Gegenwart konkurrierte und von dieser allzu sehr ablenkte, dort wurde die Vergegenwärtigung der Vergangenheit lieber zurückgedrängt: Denn weder bei den Statuen auf dem Capitol, noch bei denen auf dem Forum war es möglich, die Präsenz der bisherigen Monumente derart zurückzunehmen und sie derart zu einer orchestrierenden Staffage umzufunktionalisieren, dass sie den Monumenten des neuen Herrschers nicht die Aufmerksamkeit stahlen und nicht mit ihnen zu laut kon-

77 Zur Pompa funebris des Augustus: Cass. Dio 56,34,2; ferner: Zanker (1987) 215; Itgenshorst (2004) 456-457; Itgenshorst (2005) 225.

78 Walter (2004) 4I7-422 betont am Beispiel des Augustusforums und seiner Statuenausstattung zu Recht den Aspekt einer Kanonisierung von Geschichte: „Von Kanonisierung kann man deshalb sprechen, weil in dieser Ruhmeshalle nicht einfach Statuen aufgestellt, sondern ein Statuenprogramm präsentiert wurde, das - anders als die agonal-polysemen republikanischen Denkmäler - keinen Raum für Zusätze, Alternativen oder Widersprüche bot“.

79 Statue des Augustus im Zentrum des Augustusforums: Zanker (I968) I2; Zanker (I987) 2I6; Spannagel (I999) II, 20, 88, I93, 34I, 357; Schollmeyer (200I) I52-I53; Meneghini - Santangeli Valenzani (2007) 59-60. Die „Vereinnahmung der Geschichte“ bes. eindrücklich bei Walter (2004) 4I9-422 herausgearbeitet, zum generellen Umgang mit Vergangenheit und zur Instrumentalisierung von Geschichte unter Augustus a.a.O. $408-426$. 
kurrierten. ${ }^{80}$ Entsprechend musste dort also die Vergangenheit zurückgedrängt und der Inszenierung der Gegenwart die Bühne im öffentlichen Raum abgetreten werden.

\title{
5. Das Forum unter Augustus: Neuerfindung einer kompensierenden Vergangenheitspräsenz
}

\begin{abstract}
Allerdings wäre es falsch, dem Forum Romanum am Übergang von der Republik zur Kaiserherrschaft jegliches Interesse an der Vergegenwärtigung der Vergangenheit abzusprechen. ${ }^{8 \mathrm{I}}$ Es scheint damals ein anderer Dialog mit der Vergangenheit aufgekommen zu sei, den man wohl kaum anders als Reaktion, vielleicht sogar als bewusste Kompensation der geschlagenen Wunde in der Erinnerungskultur am Forum bewerten kann..$^{82}$ Etwa gleichzeitig - soweit wir das bei der nicht immer klaren Chronologie der Befunde am Forum überhaupt sagen können - scheint an die Stelle der reduzierten Statuenbespielung eine neue Form der Präsenz von Vergangenheit getreten zu sein, die einen anderen, leiseren Dialog mit der Gegenwart bedingte..$^{3}$

Dabei war es vor allem nun auch eine andere Art von Vergangenheit, die in den Blick geriet: An der Stelle der Geschichte des republikanischen Roms trat die mythische Frühzeit, mit der Gründung Roms und den ersten Bewährungen seiner Bürgerschaft. ${ }^{84}$ Vor allem das entmachtete und entfunktionalisierte Comitium avancierte dabei zu einer my-
\end{abstract}

8० Zu der grundsätzlich komplexen und in ihrer Wahrnehmbarkeit schwer strukturier- und kontrollierbaren Situation der Monumente auf dem spätrepublikanischen Forum s. auch Walter (2004) I57-160; im Vergleich mit dem Augustusforum a.a.O. 420.

8I Grundsätzlich zur Umwandlung des Forums unter Augustus, sowohl in der Zurückdrängung der dort präsenten Vergangenheit, als auch in der Etablierung eines neuen Umgangs mit der Vergangenheit: Zanker (I972) 8-25, 42-49; Coarelli (I985) 258-324; Zanker (I987) 85-87 und passim; Stambaugh (I988) II6-II9; Wallace-Hadrill (I993) 5I-55; Kolb (I995) 350-358; Purcell (I995) 337-339; Favro (I996) I95-200, 273-276; Kissel (2004) 323-337; Knell (2004) 36-50, I04-IO6; Hölscher (2006) II3-II6; Haselberger (2007) 57-59, 73-77, 8I, I8I, 2II-2I9; Freyberger (2009a) 58-83; Freyberger (2009b) I55-I58; Muth (2009) bes. 34I-345; Muth (20II) $27 \mathrm{I}-272$.

82 Hierzu auch Muth (20II) 272, als Kompensation im Kontext der weitgreifenden architektonischen und räumlichen Umstrukturierung des Forums. Wallace-Hadrill (I993) 5I betont zu Recht die Inszenierung der mythischen Stätten (,$\ldots$ we might think of his Forum as a new creation, carefully ,antiqued “ a.a.O.)

83 Wobei auch hier, wie im Fall des Umgangs mit den Monumenten auf dem Forum, keineswegs gesagt sein soll, dass dies alles erst unter Augustus aufkam. Die Tendenzen eines solchen grundsätzlichen Interesses an der wachsenden Auseinandersetzung mit mythischen Erinnerungsorten scheinen sich im Laufe des I. Jahrhunderts v. Chr. abzuzeichnen. Bezeichnend aber ist für die augusteische Zeit, dass diese Strukturen verstärkt akzentuiert werden; zu der neuen Form der Vereinnahmung von Geschichte unter Augustus s. auch Walter (2004) 408-426, bes. 419-422; zum aufkommenden Interesse an einer Topographie der Geschichte im I. Jh. v. Chr. a.a.O. I75-I79. - S. auch die Ausführungen von St. Freyberger in diesem Band: Die hier besprochenen Monumente und Bauten am Forum, die auf die Gründungsgeschichte Roms verweisen, erfahren größtenteils eine Erneuerung ebenfalls in augusteischer Zeit, werden somit bewusst aktualisiert.

84 Generell zum Phänomen der mythischen Erinnerungsstätten in der Topographie Roms, unter Betonung ihres anders gelagerten, stärker ein „patriotisches Erleben“ forcierenden Wirkungspotentials: Hölscher (200I) 202-204 (Zitat ebd. 204). 


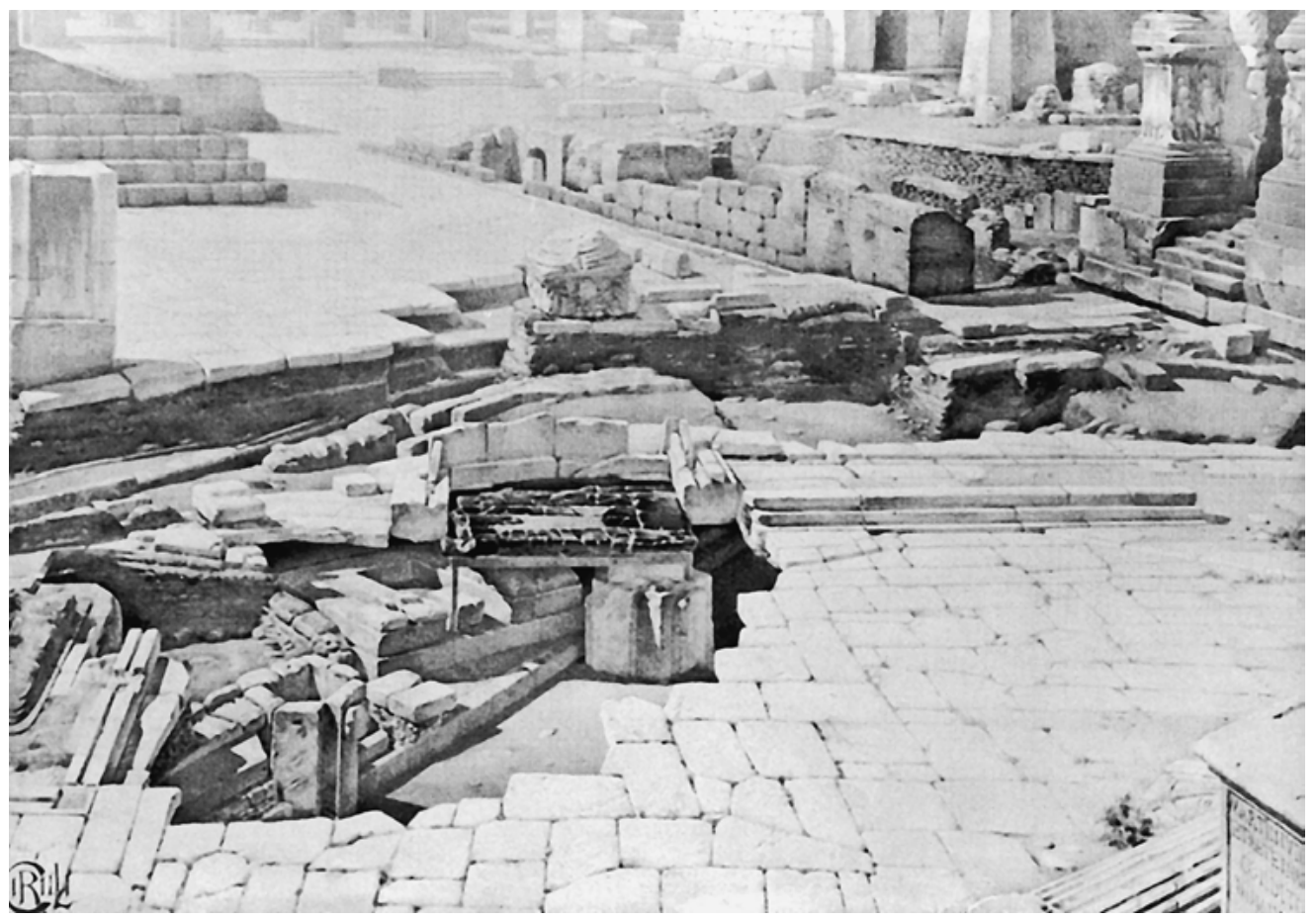

Abb. 19 | Comitium mit dem Lapis niger und dem darunter liegenden Heiligtum während der Ausgrabungen unter G. Boni (I899-1900), Zeichnung Cirilli

thischen Erinnerungsstätte..$^{85}$ Bezeichnend ist dort etwa die Inszenierung des Lapis niger, einer betont herausgehobenen Fläche mit dunkler Plattenpflasterung und begrenzender Brüstung (Abb. 19-20). ${ }^{86}$ Einst markierte die Fläche die Stelle eines Heiligtums, das im Rahmen des Umbaus des Comitiums unter Sulla oder Caesar zerstört wurde. ${ }^{87}$ Doch aufgrund der diffusen Kennzeichnung dessen, was hier markiert wurde, - der Lapis niger ist eigentlich primär nur Markierung von etwas, ohne dass die Konzeption der Markierung

85 S. hierzu Muth (20II) 272 sowie ausführlicher demnächst in einer Arbeit zur Rolle authentischer Erinnerungsorte in der Topographie Roms. - Vgl. auch Walter (2004) 425-426, der überzeugend auf die virtuelle Bedeutungsaufladung des Comitiums bei Livius als „Ort großer Ereignisse“ verweist.

86 Zum Befund des Lapis Niger: Zanker (I972) 25; Coarelli (I983) I35-I36, I6I-226, bes. I65-I69, I7I-I77, I88-I89; Coarelli (I985) I95-I98, 234; Coarelli (I993a) 3І2-3I3; Wallace-Hadrill (I993) 5I; Gros u. Torelli (I994) 28-29; Kolb (I995) 77-8I, 254; Favro (I996) 37, 66; Carafa (I998) I02-I05, III-II4, I5I-I55, I59; Coarelli (I999a) 213; Coarelli (I999c); Coarelli (I999d) 2II; Köb (2000) I7-23; Hölscher (2006a) I05-Io6; Freyberger (2009a) I4-I8.

87 Die genaue Chronologie der Zerstörung ist umstritten. Coarelli datiert sie in sullanische Zeit, Carafa in caesarische Zeit, s. etwa: Coarelli (I983) I35-I36; Coarelli (I993a) 3І2-3І3; Coarelli (I999c\&d); Carafa (I998) 86, I5I-I55, I59. 


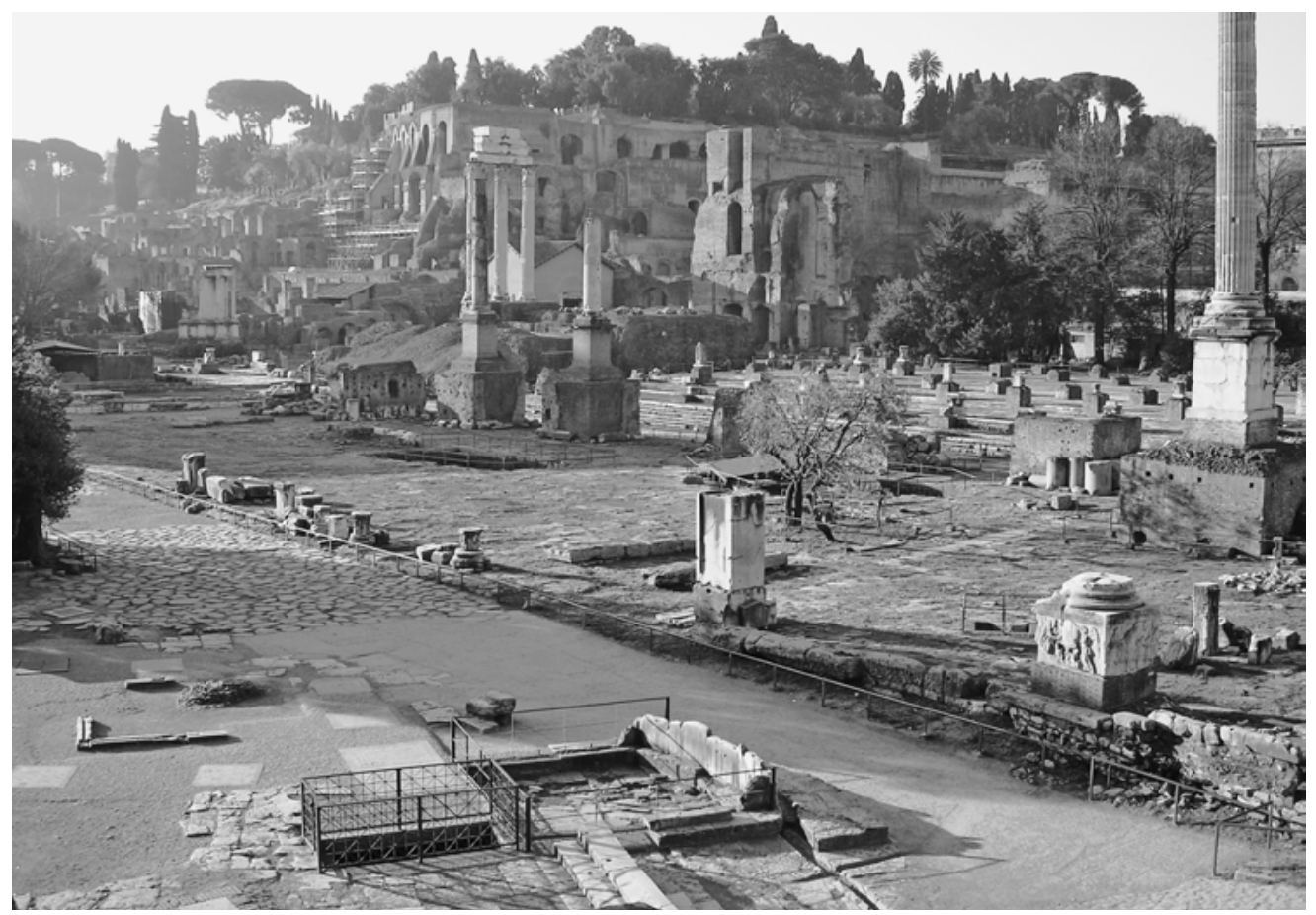

Abb. 20 | Ansicht des Forums mit dem Comitium und dem Lapis niger im Vordergrund

verrät, was sie eigentlich markiert (was angesichts des eigentlichen Grundes für die Markierung auch verständlich ist: hier konnte nur jeder hoffen, dass die Zerstörung des Heiligtums schnell vergessen ging) - rankten sich dann schon bald, das heißt bezeugt in augusteischer Zeit, ganz andere Deutungen um diese herausgehobene Stelle: Man vermutete hier den Ort, an dem Romulus ermordet wurde bzw. wo sich seine Apotheose vollzog, oder man lokalisierte hier das Grab des Hirten Faustulus, oder aber das des Hostus Hostilius, eines Mitstreiters Romulus im Kampf gegen die Sabiner. ${ }^{88}$ Aber auch gleichgültig, was man hier lokalisierte, es führte bis weit in die mythische Frühzeit Roms zurück - und machte diese zugleich durch die topographische Fixierung authentisch und

88 Die verschiedenen Versionen finden sich bei Festus überliefert, Fest. I84 L: Niger lapis in Comitio locum funestum significat, ut ali, Romuli morti destinatum, sed non usu ob in<ferias ... Fau>stulum nutri<cium eius aut ali, Hostum Hos>tilium avum Tu<lli Hostilii, Romanorum regis cuius familia e Medullia Romam venit post destruc>tionem eius; entsprechende Angaben finden sich auch bei Dion. Hal. ant. I,87,2 ff. (Grab des Faustulus), 3,I,2 (Grab des Hostus Hostilius). Daneben wird rekurrierend auf die Horaz-Scholiasten Ps. Acron. ad Hor. epod. 6,I3 und Porph. ad Hor. epod. 6,I3 (nam Varro post rostra fuisse sepulcrum Romuli dicit) teils auch das Grab des Romulus hier erwogen. Ausführlichere Diskussion der verschiedenen literarischen Zeugnisse: Coarelli (I983) I66-I68; Carafa (I998) III-II4; Coarelli (I999c). 
somit erlebbar. ${ }^{89}$ Nahe beim Lapis niger stand die Statue der Lupa, und nahe dieser wiederum die Ficus Ruminalis, in ihrer Kombination die alte Stätte des Lupercals virtuell am Forum sichtbar machend. $9^{\circ}$ Alles in allem entstand hier also ein Ensemble, das die mythische Frühzeit in einer Massivität plötzlich präsent machte, wie sie es am Forum zuvor nie gewesen war. Das entmachtete Comitium wandelte sich gewissermaßen zu einem mythischen Erinnerungsreservat und gewann dadurch seine neue Bedeutung am kaiserzeitlichen Forum.

Doch beschränkte sich die Erinnerung an die mythische Vorzeit nicht allein auf die Fläche des alten Comitiums. Auch an anderen Stellen der Topographie des Forums wurde die Erinnerung an die mythische Frühzeit aktiviert (Abb. 2I). So wusste man nun verschiedene Ereignisse des Kampfes zwischen den Römern und den Sabinern hier zu lokalisieren:9i Der Bündnisschluss zwischen Romulus und Titus Tatius soll entweder am Comitium oder nach anderen Versionen an der Via sacra erfolgt sein9²; am Heiligtum der Venus Cloacina sollen die geraubten Sabinerinnen Römer und Sabiner miteinander versöhnt haben 93 (Abb. 22); über den Lacus Curtius wusste man ebenfalls verschiedene Versionen zu berichten, welcher Reiter sich aus welchem Anlass hier in den Sumpf gestürzt hätte94 (Abb. 23-24). Die Ungenauigkeit in den verschiedenen Versionen macht deutlich, dass vor Ort keine klaren Indizien gegeben wurden, durch Inschriften oder Bilder, welches mythi-

89 Dass man diesem markierten Erinnerungsort der mythischen Frühzeit große Bedeutung beimaß, zeigt sich nicht zuletzt auch darin, dass man ihn derart weit in die Straßenführung zwischen Comitium und Forum hineinragen und die Breite der Straße an dieser prominenten Stelle im Areal des Forum Romanum dadurch merklich verengen ließ.

90 Lupa und Ficus Ruminalis: s.o. Anm. 23-24, 53.

9I Bezeichnend ist hier vor allem die Schilderung bei Livius (Liv. I,I2-I3), der die Ereignisse des Kampfes mit konkreten topographischen Punkten am Forum verknüpft; andere Überlieferungen variieren zum Teil in der topographischen Lokalisierung. Hierzu s. auch Hölscher (2006a) I04-I05; Carafa (2000).

92 Lokalisierung des Bündnisschlusses zwischen Romulus und Titus Tatius: Comitium: Plut. Rom. 19,7; Cass. Dio fr. 5,7; - via sacra: Dion. Hal. ant. 2,46,3; Plin. nat. 15,II9; Fest. 372 L. S. hierzu Coarelli (1993a) 3II; Walter (2004) 156.

93 Lokalisierung des Eingreifens der Sabinerinnen und des Ablegens der Waffen: Plin. nat. 15,II9. - Zum Heiligtum der Venus Cloacina: Coarelli (I983) 83-86; Coarelli (I993c); Köb (2000) 36-40; Freyberger (2009a) II, I4-I5; s. auch hier Freyberger unten S. 52 f. - Die neuen Untersuchungen zur Basilica Aemilia haben weitere kleinere Heiligtümer vor der Südseite der Basilica, welche ebenfalls alte Mäler am augusteischen Forum markierten, entdecken lassen, s. hierzu Freyberger (2009a) II-I5 sowie in diesem Band 5I-57.

94 Lacus Curtius als Erinnerungsort: Während der mythischen Schlacht zwischen Römern und Sabinern soll der sabinische Reiter Mettius Curtius auf der Flucht in einen Sumpf gestürzt sein, woher der Ort seinen Namen erhält (Varro ling. 5,I48; Liv. I,I2,9; Dion. Hal. ant. 2,42;I6,II; Plut. Rom. I8); daneben wird aber auch eine andere Version tradiert, nach der der römische Reiter Marcus Curtius sich im Jahr 362 v. Chr. in Reaktion auf einen Orakelspruch selbst opfert und sich in den Schlund stürzt, woraufhin sich dieser wieder schließt (Varro ling. 5,I48; Liv. 6,6,I-6; Dion. Hal. ant. I6,II,I-5; Val. Max. 5,6,2); schließlich wird als dritte Version aber auch berichtet, der Consul Curtius hätte im Jahr 445 v. Chr. diesen Bezirk, nachdem ein Blitz eingeschlagen hatte, sakral gefasst (Varro ling. 5,I50). - Zum Lacus Curtius: Zanker (I972) 25, 37 Anm. I64; Coarelli (I985) 226-229; Giuliani u. Verduchi (1987) I05-II6; Giuliani (1996); Köb (2000) 27-30; Walter (2004) 156; Freyberger (2009a) I8-20. 
Comitium:

Friedenschluß zwischen

Romulus \& Titus Tatius
Heiligtum der Venus Cloacina:

Geraubte Sabinerinnen versöhnen Römer \& Sabiner

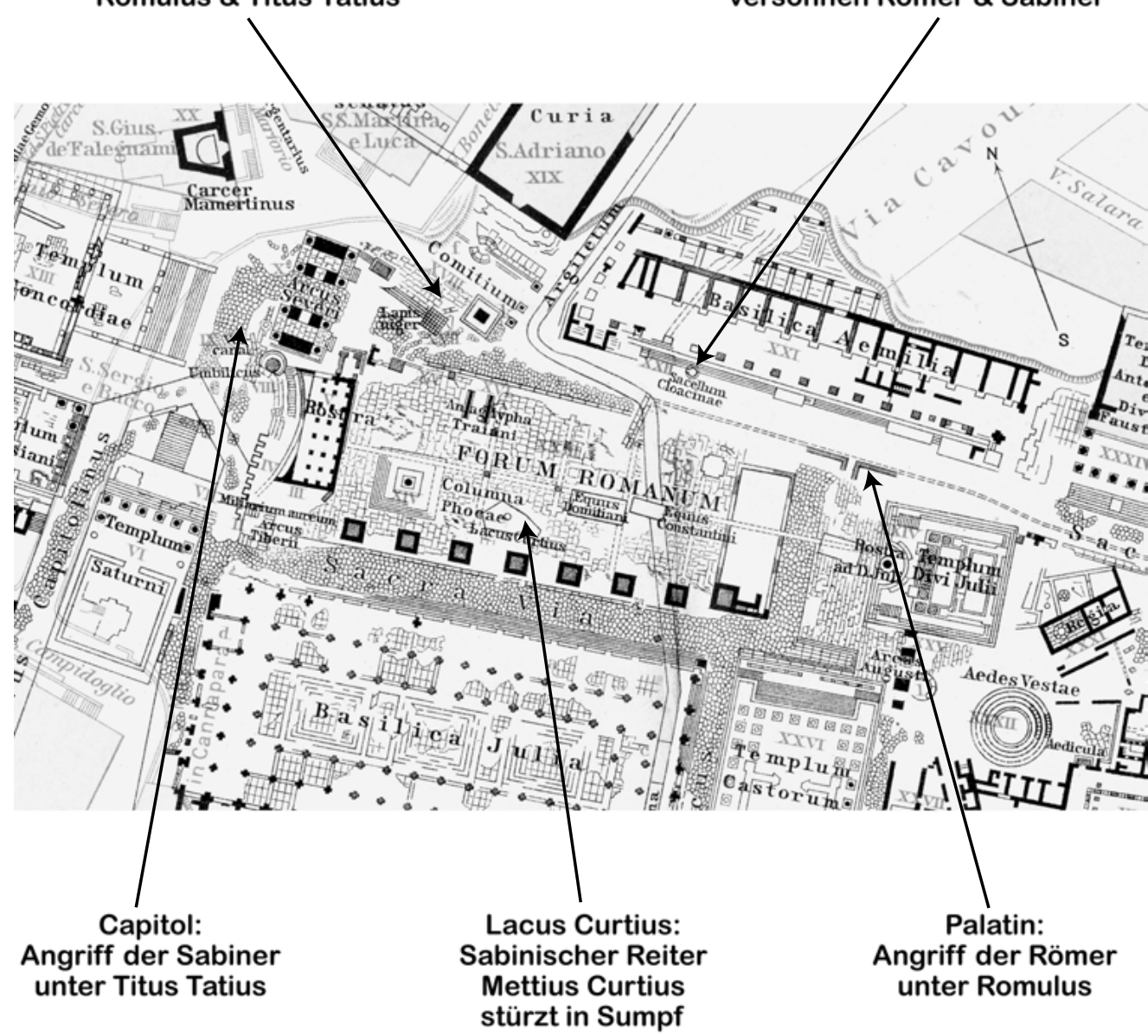

Abb. 21 | Das Forum als Schauplatz des mythischen Kampfes zwischen Römern und Sabinern nach der Schilderung bei Livius, ab urbe condita, I, I2-I3 


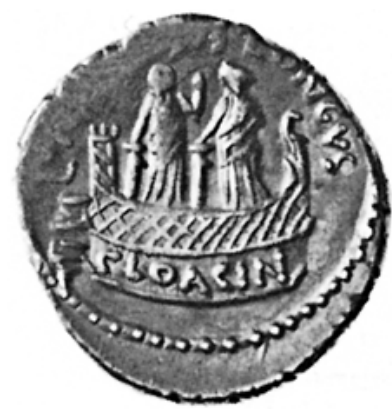

Abb. 22 | Sacellum der Venus Cloacina, Denar des L. Mussidus Longus, 42 v. Chr.

sche Ereignis mit dem Ort zu identifizieren sei (was man leicht hätte tun können, wenn man es gewollt hätte)95. Das heißt: Die neu gesuchte und konstruierte Inszenierung der Vergangenheit am Forum blieb alles in allem eher zurückhaltend, zum Teil sogar diffus und gewinnt keineswegs die visuelle und ideelle Präsenz, wie sie die republikanischen Ehrenstatuen und Monumente einst innegehabt hatten..$^{6}$

Zudem werden nun auch mehr Ereignisse und Taten memoriert und nicht in erster Linie Personen herausgehoben: dort starb Romulus, hier wurde Faustulus bestattet, dort vereinigten sich Romulus und Titus Tatius, hier stürzte Mettius Curtius in den Sumpf, etc. Das ist strukturell eine ganz andere Art der Vergegenwärtigung von Vergangenheit, konzentriert auf Orte und Ereignisse und weniger fixiert auf die ganzheitliche Rühmung von Personen, was vielleicht im Klima des monarchisch regierten Roms leichter ertragbar war als Kontrapunkt zur Gegenwart - und leichter kontrollierbar und lenkbar, als es die in ihrer visuellen Präsenz viel aufdringlicheren Monumente des republikanischen Forums waren. Man breitete nun einfach in neuer Weise die Handlungstopographie einer weit zurückliegenden mythischen Vergangenheit über das Forum aus, schuf gewissermaßen eine ideell

95 Allein beim Lacus Curtius wies eine Reliefdarstellung an einer Schranke, die zur augusteischen Umschrankung des Heiligtums gehört, auf das Ereignis des Reitersturzes hin (die Datierung des Reliefs ist umstritten, die Vorschläge reichen vom 2.-I. Jh. v. Chr. [so Freyberger (2009a) I9] bis zum I. Jh. v. Chr. - 4. Jh. n. Chr. [so Carafa (2000) 333]). Allerdings thematisiert die Darstellung auch nur das eigentliche Ereignis des Sturzes, ohne eine Verankerung in den verschiedenen vorgeschlagenen Handlungssituationen zu konkretisieren.

96 Neben den genannten gab es noch weitere mythhistorische Erinnerungsorte am Forum, die ebenfalls einzelne Ereignisse der Gründungsgeschichte bzw. Königszeit Roms memorierten: I) Der Mundus im Bereich des Comitiums, der teils mit dem Umbilicus Urbis identifiziert wird, soll Romulus als Mittelpunkt bei Anlage der Stadtgrenze Roms gedient haben: Wallace-Hadrill (I993) 5I; Kolb (I995) 75-76; Coarelli (I996b); Freyberger (2009a) I8-I9. - 2) Die Regia galt als das ursprüngliche Wohnhaus des Königs Numa Pompilius: Scott (I999a) I89; Freyberger (2009a) 23. Auch der benachbarte Tempel der Vesta wurde auf die Königszeit zurückgeführt; als Indiz für diesen Ursprung wertete man ihre Form als Tholos, die man aus der Abhängigkeit von der einstigen runden Hütte erklärte: Scott (I999b) I25; Freyberger (2009a) 23. - 3) Der Lacus Iuturnae war vor allem als Ort, an dem die Dioskuren nach der Schlacht beim See Regillus erschienen, bekannt; darüber hinaus war er aber auch indirekt mit den Ereignissen der Landung des Aeneas in Italien und seines Kampfes gegen Turnus, als dessen Schwester Iuturna galt, verbunden: Wallace-Hadrill (I993) 51; Steinby (I996); Walter (2004) I46-I48; Freyberger (2009a) 32. 


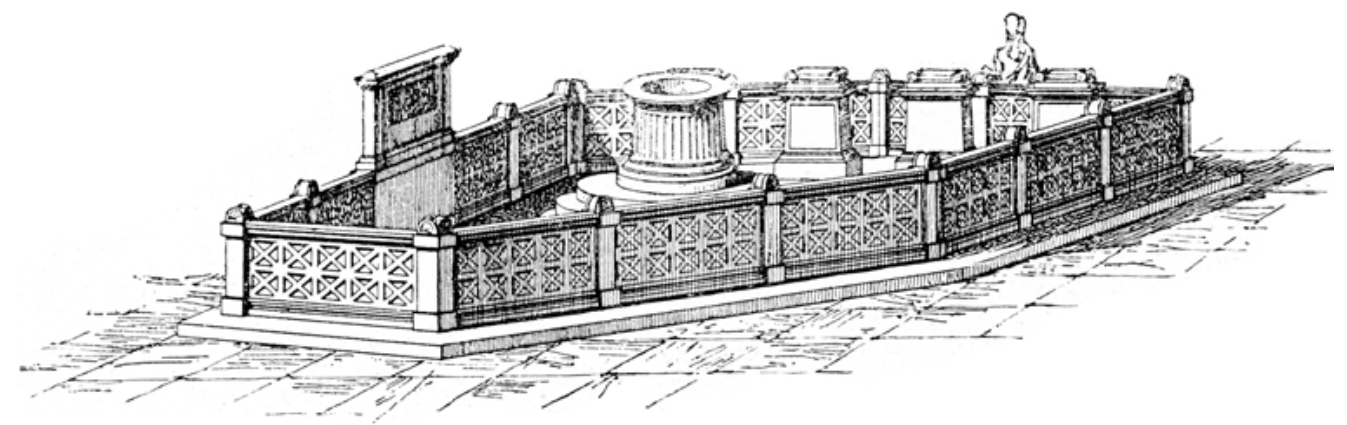

Abb. 23 | Rekonstruktion des Lacus Curtius

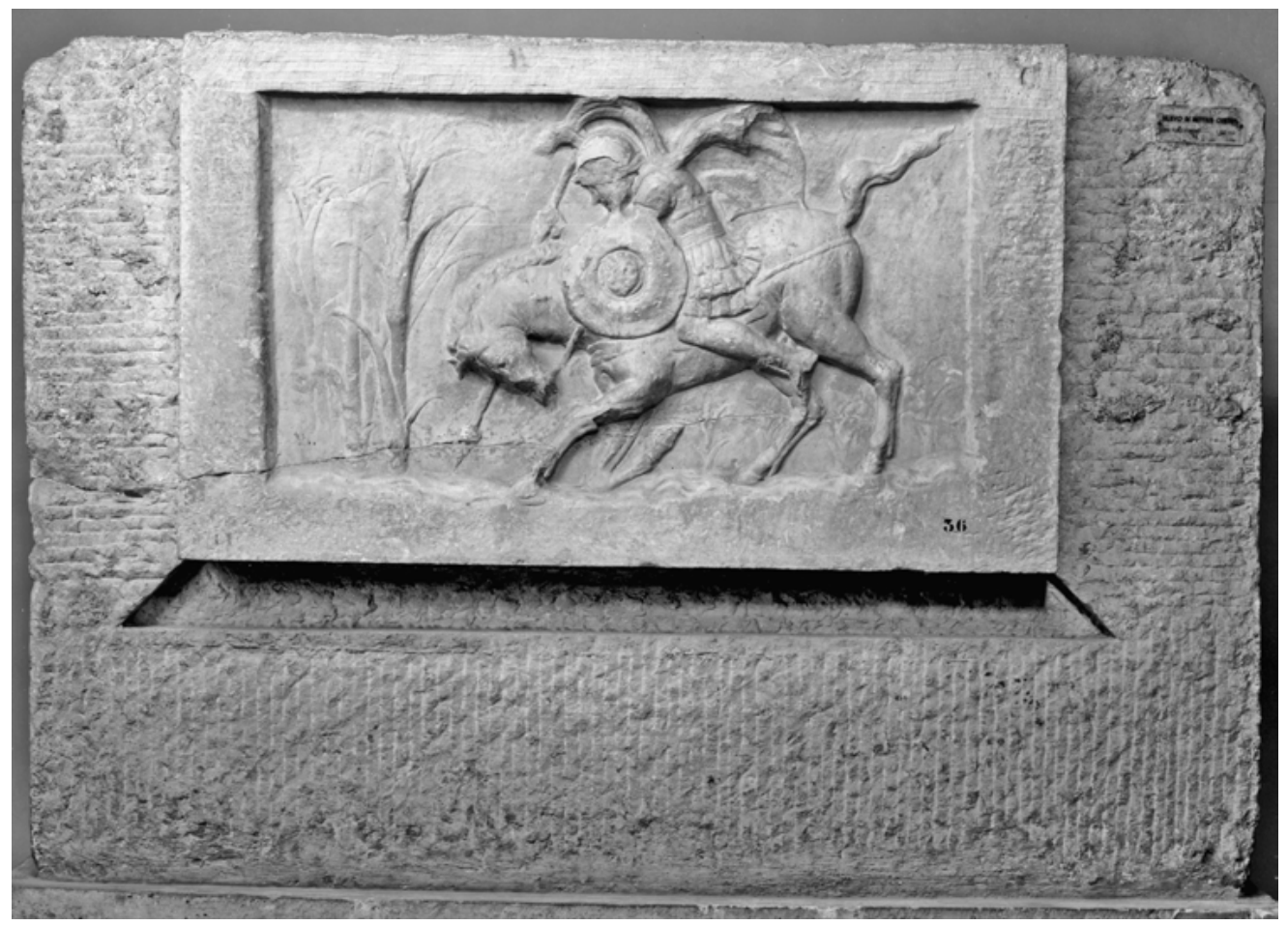

Abb. 24 | Relief von der Brüstung des Lacus Curtius mit Darstellung eines sich in den Sumpf stürzenden Reiters, Rom, Musei Capitolini, Palazzo dei Conservatori, Braccio Nuovo, Inv.-Nr. 826. 
aufgeladene Bühne, auf der sich dann das Treiben der Gegenwart frei entfalten und um so eindrucks- und wirkungsvoller erheben konnte. 97

\section{Fazit: Wandel von einer aristokratisch geprägten hin zu einer monarchisch funktionierenden Stadt - und die Konsequenzen für die Erinnerungskultur}

Unsere Betrachtung hat gezeigt, dass es an der Wende von der Republik zur Kaiserherrschaft im öffentlich-politischen Raum zu einer merklichen Zäsur in der Vergegenwärtigung von Vergangenheit kam. Anstatt der Vergangenheit eine starke und konkurrenzfähige Präsenz zuzugestehen, welche sie auch in das diskursive Klima des öffentlichen Raumes nachhaltiger wirken ließ - eine Praxis, welche sich zuvor im aristokratisch organisierten Rom der Republik bei der Bespielung des öffentlich-politischen Raums durch Monumente und Statuenaufstellung etabliert hatte, - kam es mit der Hinwendung zu einer monarchisch funktionierenden Stadt zu einer stärker restriktiven und deutlich kontrollierten Präsenzmachung von Vergangenheit: Vergangenheit wurde nur noch dort und dann gegenwärtig gehalten, wo sie in einer klaren Bezugnahme und Hinführung auf die Gegenwart vermittelbar war und wo sie keine Aufmerksamkeit erheischenden Auftritte beanspruchte. Dies wurde unter anderem dadurch erwirkt, dass statt der Vergangenheit der glorreichen Epochen der Republik nun die weiter zurückliegende und daher weniger als Konkurrenz wahrnehmbare mythische Vergangenheit aufgegriffen wurde, - und dass die Erinnerungsmale zudem weniger direkt auf Personen als Leistungsträger konzentriert waren, als vielmehr auf Orte einzelner Ereignisse. Der Beitrag, den die neu organisierte Erinnerung an die Vergangenheit für das diskursive Klima an diesen Orten der politischen Kommunikation nun evozierte, war von grundlegend anderer Dimension. ${ }^{8}$ Trotz aller

$97 \mathrm{Zu}$ Recht betont Walter (2004) I55-I95, bes. I62-I64 das gesteigerte Potential solcher auf die Authentizität des Ortes rekurrierenden Erinnerungsorte, woraus die Erinnerungs- und Geschichtskultur eine besondere Wirkungskraft zu entwickeln vermögen. Doch die Themen, an die diese Geschichtsorte erinnerten, vermochten dennoch nur wenig mit den ideologischen Ansprüchen zu konkurrieren, die die Ehrenstatuen und Siegesmonumente präsent hielten und die auch zentralere Themen im Diskurs des aktuellen Herrschaftsverständnisses des Augustus besaßen. - Die folgenden Beispiele einer mythisch-authentischen Erinnerungstopographie jenseits des Forums zeigen eine Neugestaltung und somit Neuakzentuierung in augusteischer Zeit bzw. werden gar als augusteische Neuerfindung zur Visualisierung der mythischen Vergangenheit im Stadtbild Rom angesprochen: I) Die zwei Hütten des Romulus, die eine auf dem Capitol, die andere auf dem Palatin: Coarelli (I993d); Haselberger (2002) 53, 83; Walter (2004) I79-I83. - 2) Das Lupercal: Coarelli (I996a); Haselberger (2002) I62; Carandini - Bruno (2008) 4-29, I22-I37. - 3) Reste der Stadtmauer des Romulus, deren Verlauf am Clivus Palatinus durch augusteische(?) Cippi markiert wurde: Tomei (I997) 36-37; D’Alessio (2000). - Allgemein zur Erinnerungstopographie Roms s. ferner: Hölscher (200I); Hölkeskamp (2004) I37-I68; Hölscher (2006a) I03-IO6; sowie demnächst Muth ausführlicher zur Rolle der Erinnerungsorte in der Topographie des spätrepublikanischen und kaiserzeitlichen Roms.

$98 \mathrm{Zu}$ den grundlegenden Zäsuren im Funktionieren einer politisch motivierten Erinnerungskultur an dem Übergang von der späten Republik zur Monarchie s. auch im weiteren Kontext Walter (2004) 408-426; Gowing (2005) I35-I45. 
Vision von der wiederhergestellten Res publica und trotz aller Beschwörungen, die alten Traditionen des republikanischen Roms zu wahren, wie Augustus dies seine Zeitgenossen glauben machen wollte: Die veränderte Modellierung des öffentlichen Raumes als Bühne der politischen und identitätsstiftenden Kommunikation - mit ihren neuen Formen einer reglementierten Erinnerungskultur - verriet deutlich, zu welch gravierendem Bruch es damals gekommen war.

\section{Bibliographie}

\section{Bauer (1996)}

Franz Alto Bauer, Stadt, Platz und Denkmal in der Spätantike, Mainz.

Bergemann (1990)

Johannes Bergemann, Römische Reiterstatuen. Ehrendenkmäler im öffentlichen Bereich, Mainz.

Carafa (1998)

Paolo Carafa, Il Comizio di Roma dalle origini all'età di Augusto, Roma.

Carafa (2000)

Paolo Carafa, „La battaglia nel Foro“, in: Andrea Carandini u. Rosanna Cappelli (Hgg.), Roma: Romolo, Remo e la fondazione della citta, Ausstellungskatalog, Roma, 333-335.

Chioffi (1993)

Laura Chioffi, „Columna rostrata C. Duilii“, in: Eva Margareta Steinby (Hg.), Lexicon Topographicum Urbis Romae, Bd. I, Roma, 309.

Coarelli (1983)

Filippo Coarelli, Il Foro Romano I. Periodo Arcaico, Roma.

\section{Coarelli (1985)}

Filippo Coarelli, Il Foro Romano II. Periodo Repubblicano e Augusteo, Roma.

\section{Coarelli (1993a)}

Filippo Coarelli, „Comitium“, in: Eva Margareta Steinby (Hg.), Lexicon Topographicum Urbis Romae, Bd. I. Roma, 309-3I4.

\section{Coarelli (1993b)}

Filippo Coarelli, „Curia Hostilia“, in: Eva Margareta Steinby (Hg.), Lexicon Topographicum Urbis Romae, Bd. I. Roma, 33I-332.

\section{Coarelli (I993C)}

Filippo Coarelli, „Cloacina, sacrum“, in: Eva Margareta Steinby (Hg.), Lexicon Topographicum Urbis Romae, Bd. I. Roma, 290-29I.

\section{Coarelli (I993d)}

Filippo Coarelli, „Casa Romuli (area Capitolina) \& (Germalus)“, in: Eva Margareta Steinby (Hg.), Lexicon Topographicum Urbis Romae, Bd. I. Roma, 24I-242. 


\section{Coarelli (1995)}

Filippo Coarelli, „Ficus Navia; Ficus Ruminalis“, in: Eva Margareta Steinby (Hg.), Lexicon Topographicum Urbis Romae, Bd. II. Roma, 248-249.

\section{Coarelli (1996а)}

Filippo Coarelli, „Lupercal“, in: Eva Margareta Steinby (Hg.), Lexicon Topographicum Urbis Romae, Bd. III. Roma, I98-I99.

\section{Coarelli (1996b)}

Filippo Coarelli, „Mundus“, in: Eva Margareta Steinby (Hg.), Lexicon Topographicum Urbis Romae, Bd. III. Roma, 288-289.

\section{Coarelli (1999a)}

Filippo Coarelli, „Rostra (età repubblicana)“, in: Eva Margareta Steinby (Hg.), Lexicon Topographicum Urbis Romae, Bd. IV. Roma, 2I2-2I4.

\section{Coarelli (1999b)}

Filippo Coarelli, „Statua“, in: Eva Margareta Steinby (Hg.), Lexicon Topographicum Urbis Romae, Bd. IV. Roma, 36I-369.

\section{Coarelli (I999C)}

Filippo Coarelli, „Sepulcrum Romuli“, in: Eva Margareta Steinby (Hg.), Lexicon Topographicum Urbis Romae, Bd. IV. Roma, 295-296.

\section{Coarelli (I999d)}

Filippo Coarelli, „Volcanal“, in: Eva Margareta Steinby (Hg.), Lexicon Topographicum Urbis Romae, Bd. V. Roma, 209-2II.

\section{D'Alessio (2000)}

Maria Teresa D’Alessio, „Cippi iscritti dal Clivo Palatino“, in: Andrea Carandini u. Rosanna Cappelli (Hgg.), Roma: Romolo, Remo e la fondazione della città, Ausstellungskatalog, Roma, 290-29I.

\section{Degrassi (1945-46)}

Attilio Degrassi, „L'edificio dei Fasti Capitolini“, Rendiconti. Atti della Pontificia accademia romana di archeologia 2I, 57-IO4.

Delitz (2009)

Heike Delitz, Architektursoziologie, Bielefeld.

\section{Delitz (20I0)}

Heike Delitz, Gebaute Gesellschaft. Architektur als Medium des Sozialen, Frankfurt / New York.

\section{Dulière (1979)}

Cecile Dulière, Lupa Romana. Recherches d'iconographie et essai d'interpretation, Paris.

\section{Favro (1996)}

Diane Favro, The Urban Image of Augustan Rome, Cambridge / New York. 
Fischer u. Delitz (2009)

Joachim Fischer u. Heike Delitz (Hgg.), Die Architektur der Gesellschaft. Theorien für die Architektursoziologie, Bielefeld.

Freyberger (2009a)

Klaus Stefan Freyberger, Das Forum Romanum. Spiegel der Stadtgeschichte des antiken Rom, Mainz.

Freyberger (2009b)

Klaus Stefan Freyberger, „Il foro Romano“, in: Henner von Hesberg u. Paul Zanker (Hgg.), Architettura romana: I grandi monumenti di Roma, Milano, I52-I63.

Freyberger (2009c)

Klaus Stefan Freyberger, „Le basiliche“, in: Henner von Hesberg u. Paul Zanker (Hgg.), Architettura romana: I grandi monumenti di Roma, Milano, I64-I7I.

\section{Ganzert u. Kockel (1998)}

Joachim Ganzert u. Valentin Kockel, „Augustusforum und Mars-Ultor-Tempel“, in: Kaiser Augustus und die verlorene Republik. Katalog der Ausstellung Berlin, 7. 6.-I4. 8. I988, Berlin, I49-199.

Gatti (1945-46)

Gugliemo Gatti, „La ricostruzione dell'arco di Augusto al foro Romano“, Rendiconti. Atti della Pontificia accademia romana di archeologia 2I, IO5-I22.

\section{Geiger (2008)}

Joseph Geiger, The First Hall of Fame. A Study of the Statues in the Forum Augustum, Leiden / Boston.

\section{Giuliani (1996)}

Cairoli Fulvio Giuliani, „Lacus Curtius“, in: Eva Margareta Steinby (Hg.), Lexicon Topographicum Urbis Romae, Bd. III, Roma, I66-167.

Giuliani u. Verduchi (1987)

Cairoli Fulvio Giuliani u. Patrizia Verduchi, L'area centrale del foro Romano, Firenze.

\section{Giuliani u.Verduchi (1995)}

Cairoli Fulvio Giuliani u. Patrizia Verduchi, „Forum Romanum (età tarda)“, in: Eva Margareta Steinby (Hg.), Lexicon Topographicum Urbis Romae, Bd. II, Roma, 342-343.

\section{Golvin (2005)}

Jean-Claude Golvin, Metropolen der Antike, Darmstadt.

\section{Gowing (2005)}

Alain M. Gowing, Empire and Memory. The Representation of Roman Republic in Imperial Culture, Cambridge.

Gros u. Torelli (1994)

Pierre Gros u. Mario Torelli, Storia dell' urbanistica: Il mondo romano, Bari. 


\section{Gros (1996)}

Pierre Gros, „Iulius, divus, aedes“, in: Eva Margareta Steinby (Hg.), Lexicon Topographicum Urbis Romae, Bd. III, Roma, II6-II9.

\section{Haselberger (2002)}

Lothar Haselberger, Mapping Augustan Rome, Portsmouth.

\section{Haselberger (2007)}

Lothar Haselberger, Urbem adornare. Die Stadt Rom und ihre Gestaltumwandlung unter Augustus, Portsmouth.

\section{Hölkeskamp (2004)}

Karl-Joachim Hölkeskamp, Senatus Populusque Romanus. Die politische Kultur der RepublikDimensionen und Deutungen, Stuttgart.

\section{Hölkeskamp (im Druck)}

Karl-Joachim Hölkeskamp, „Im Gewebe der Geschichte(n). Memoria, Monumente und ihre mythhistorische Vernetzung“, in: Karl Galinsky (Hg.), Memory and Roman Culture / Gedächtnis und Römische Kultur, Konferenz Bochum I2.-I4. II. 20 IO.

\section{Hölscher (1978)}

Tonio Hölscher, „Die Anfänge römischer Repräsentationskunst“, Mitteilungen des Deutschen Archäologischen Institutes, Römische Abteilung 85, 315-357.

\section{Hölscher (1980)}

Tonio Hölscher, „Römische Siegesdenkmäler der späten Republik“, in: Herbert A. Cahn u. Erika Simon (Hgg.), Tainia. Festschrift für Roland Hampe, Mainz, 35I-37I.

\section{Hölscher (200I)}

Tonio Hölscher, „Die Alten vor Augen. Politische Denkmäler und öffentliches Gedächtnis im republikanischen Rom“, in: Gert Melville (Hg.), Institutionalität und Symbolisierung. Verstetigungen kultureller Ordnungsmuster in Vergangenheit und Gegenwart, Köln / Weimar / Wien, I83-2II.

\section{Hölscher (2006a)}

Tonio Hölscher, „Das Forum Romanum - die monumentale Geschichte Roms“, in: Elke Stein-Hölkeskamp u. Karl-Joachim Hölkeskamp (Hgg.), Erinnerungsorte der Antike. Die römische Welt, München, I00-I22.

\section{Hölscher (2006b)}

Tonio Hölscher, „Macht, Raum und visuelle Wirkung: Auftritte römischer Kaiser in der Staatsarchitektur von Rom“, in: Joseph Maran, Carsten Juwig, Hermann Schwengel u. Ulrich Thaler (Hgg.), Constructing Power. Architecture, Ideology and Social Practice / Konstruktion der Macht. Architektur, Ideologie und soziales Handeln, Hamburg, I85-20I.

\section{Huelsen (1905)}

Christian Huelsen, Das Forum Romanum, seine Geschichte und seine Denkmäler, Rom.

\section{Itgenshorst (2004)}

Tanja Itgenshorst, „Augustus und der republikanische Triumph: Triumphalfasten und summi viri-Galerie als Instrumente der imperialen Machtsicherung“, Hermes 132, 436-458. 


\section{Itgenshorst (2005)}

Tanja Itgenshorst, Tota illa pompa. Der Triumph in der römischen Republik, Göttingen.

Jordan-Ruwe (1995)

Martina Jordan-Ruwe, Das Säulenmonument. Zur Geschichte der erhöhten Aufstellung antiker Porträtstatuen, Bonn.

Kent, Overbeck u. Stylow (1973)

John P.C. Kent, Bernhard Overbeck u. Armin U. Stylow, Die römische Münze, München.

Kissel (2004)

Theodor Kissel, Das Forum Romanum. Leben im Herzen Roms, Düsseldorf / Zürich.

Knell (2004)

Heiner Knell, Bauprogramme römischer Kaiser, Mainz.

Kockel (1995)

Valentin Kockel, „Forum Augustum“ in: Eva Margareta Steinby (Hg.), Lexicon Topographicum Urbis Romae, Bd. II, Roma, 289-295.

Köb (2000)

Ingrun Köb, Rom - ein Stadtzentrum im Wandel: Untersuchungen zur Funktion und Nutzung des Forum Romanum und der Kaiserfora in der Kaiserzeit, Hamburg.

Kolb (1995)

Frank Kolb, Rom. Geschichte der Stadt in der Antike, München.

\section{Kondratieff (2004)}

Eric Kondratieff, „The Column and Coinage of C. Duilius: Innovations in Iconography in Large and Small Media in the Middle Republic“, Scripta Classica Israelica 23, I-39.

\section{Lahusen (1983)}

Götz Lahusen, Untersuchungen zur Ehrenstatue in Rom, Rom.

\section{La Rocca (200I)}

Eugenio La Rocca, „La nuova immagine dei fori Imperiali: Appunti in margine agli scavi“, Mitteilungen des Deutschen Archäologischen Institutes, Römische Abteilung I08, I7I-2I3.

\section{Luce (1990)}

T. J. Luce, „Livy, Augustus, and the Forum Augustum“ in: Kurt A. Raaflaub u. Mark Toher (Hgg.), Between Republic and Empire. Interpretations of Augustus and his Principate, Berkeley / Los Angeles / London, I23-138.

Meneghini u. Santangeli Valenzani (2007)

Roberto Meneghini u. Riccardo Santangeli Valenzani, I Fori Imperiali. Gli scavi del Comune di Roma (1991-2007), Roma.

Muth (2009)

Susanne Muth, „Seiner Zeit voraus? Wie das Forum Romanum zu einer neuen Platzstruktur fand“, Wissenschaftskolleg zu Berlin, Jahrbuch 2007/2008, 324-346. 
Muth (2010)

Susanne Muth, „Auftritt auf einer bedeutungsschweren Bühne: Wie sich die Flavier im öffentlichen Zentrum der Stadt Rom inszenieren“, in: Christiane Reiz u. Norbert Kramer (Hgg.), Tradition und Erneuerung. Mediale Strategien in der Zeit der Flavier, Berlin, 485-496.

Muth (20II)

Susanne Muth, „Der Dialog von Gegenwart und Vergangenheit am Forum Romanum in Rom - oder: Wie spätantik ist das spätantike Forum?“, in: Therese Fuhrer (Hg.), Rom und Mailand in der Spätantike: Die Repräsentation des städtischen Raumes in Literatur, Architektur und Kunst, Berlin, 263-282.

\section{Nedergaard (1988)}

Elisabeth Nedergaard, „Zur Problematik der Augustusbögen auf dem Forum Romanum“, in: Kaiser Augustus und die verlorene Republik. Ausstellungskatalog Berlin 1988, Berlin, 224-239.

\section{Nedergaard (1993)}

Elisabeth Nedergaard, „Arcus Augusti (a. 29 a.C.) \& Arcus Augusti (a. I9. a.C.)“, in: Eva Margareta Steinby (Hg.), Lexicon Topographicum Urbis Romae, Bd. I, Roma, 80-85.

\section{Nedergaard (1994/95)}

Elisabeth Nedergaard, „La collocazione originaria dei Fasti Capitolini e gli archi di Augusto nel foro Romano“, Bullettino della Commissione Archeologica Comunale di Roma 96, I994/95, 33-70.

\section{Nova u. Jöchner (2010)}

Alessandro Nova u. Cornelia Jöchner (Hgg.), Platz und Territorium. Urbane Struktur gestaltet politische Räume, Berlin / München.

Palombi (1993a)

Domenico Palombi, „Columnae Rostratae Augusti“, Archeologia Classica 45, 32 I-332.

Palombi (1993b)

Domenico Palombi, „Columnae Rostratae Augusti“, in: Eva Margareta Steinby (Hg.), Lexicon Topographicum Urbis Romae, Bd. I, Roma, 308.

Papi (1995)

Emanuele Papi, „Equus“, in: Eva Margareta Steinby (Hg.), Lexicon Topographicum Urbis Romae, Bd. II, Roma, 224-233.

\section{Papi (1999)}

Emanuele Papi, „Statua: Lupa, Romulus et Remus“, in: Eva Margareta Steinby (Hg.), Lexicon Topographicum Urbis Romae, Bd. V, Roma, 290-29I.

\section{Patterson (1992)}

John R. Patterson, „The City of Rome: From Republic to Empire“, Journal of Roman Studies 82, I86-2I5.

\section{Purcell (1995)}

Nicholas Purcell, „Forum Romanum (the Imperial period)“, in: Eva Margareta Steinby (Hg.), Lexicon Topographicum Urbis Romae, Bd. II. Roma, 336-342. 
Reusser (1993)

Christoph Reusser, Der Fidestempel auf dem Kapitol in Rom und seine Ausstattung, Roma.

Roller (2009)

Matthew Roller, „The exemplary past in Roman historiography and culture“, in: Andrew Feldherr (Hg.), The Cambridge Companion to the Roman Historians, Cambridge, 2I4-230.

Schäfers (2003)

Bernhard Schäfers, Architektursoziologie. Grundlagen - Epochen - Themen, Wiesbaden.

Schmuhl (2008)

Yvonne Schmuhl, Römische Siegesmonumente republikanischer Zeit, Hamburg.

Schollmeyer (200I)

Patrick Schollmeyer, Antike Gespanndenkmäler, Hamburg.

Scott (1999a)

Russell T. Scott, „Regia“, in: Eva Margareta Steinby (Hg.), Lexicon Topographicum Urbis Romae, Bd. IV. Roma, I89-192.

Scott (1999b)

Russell T. Scott, „Vesta, aedes“, in: Eva Margareta Steinby (Hg.), Lexicon Topographicum Urbis Romae, Bd. V. Roma, I25-II8.

\section{Sehlmeyer (1999a)}

Markus Sehlmeyer, Stadtrömische Ehrenstatuen der republikanischen Zeit. Historizität und Kontext von Symbolen nobilitären Standesbewusstseins, Stuttgart.

Sehlmeyer (1999b)

Markus Sehlmeyer, „Statua“, in: Eva Margareta Steinby (Hg.), Lexicon Topographicum Urbis Romae, Bd. IV. Roma, 353-37I.

\section{Sehlmeyer (2002)}

Markus Sehlmeyer, „Die Siegesmonumente Octavians nach Actium. Zur Lokalisierung des bronzenen Viersäulendenkmals (Serv. Georg. 3,29)“, in: Jörg Spielvogel (Hg.), Res Publica Reperta. Zur Verfassung und Gesellschaft der römischen Republik und des frühes Prinzipats, Stuttgart, 216-226.

\section{Simpson (1993)}

Christopher J. Simpson, „Original Site of Fasti Capitolini“, Historia 42, 6I-8I.

\section{Spannagel (1999)}

Martin Spannagel, Exemplaria principis. Untersuchungen zu Entstehung und Ausstattung des Augustusforums, Heidelberg.

\section{Stambaugh (1988)}

John E. Stambaugh, The ancient Roman City, Baltimore / London.

\section{Stein-Hölkeskamp (im Druck)}

Elke Stein-Hölkeskamp, „Macht, Memoria und Monumente: Marius, Sulla und der Krieg um den öffentlichen Raum“, in: Karl Galinsky (Hg.), Memory and Roman Culture / Gedächtnis und Römische Kultur, Konferenz Bochum I2.-I4. II. 2010. 


\section{Steinby (1996)}

Eva Margareta Steinby, „Lacus Iuturnae“, in: Eva Margareta Steinby (Hg.), Lexicon Topographicum Urbis Romae, Bd. III, Roma, I68-I70.

Stoll (2000)

Richard Stoll, Architektur auf römischen Münzen, Trier.

Tomei (1997)

Maria Antonietta Tomei, Museo Palatino, Milano.

Torelli (I993)

Mario Torelli, „Columna Maenia“, in: Eva Margareta Steinby (Hg.), Lexicon Topographicum Urbis Romae, Bd. I, Roma, 30I-302.

\section{Tortorici (1993)}

Edoardo Tortorici, „Curia Iulia“, in: Eva Margareta Steinby (Hg.), Lexicon Topographicum Urbis Romae, Bd. I. Roma, 332-334.

\section{Trebsche, Müller-Scheeßel u. Reinhold (20I0)}

Peter Trebsche, Nils Müller-Scheeßel u. Sabine Reinhold (Hgg.), Der gebaute Raum. Bausteine einer Architektursoziologie vormoderner Gesellschaften, Münster / New York / München / Berlin.

Ulrich (1993)

Roger B. Ulrich, „Julius Caesar and the Creation of the Forum Iulium“, American Journal of Archaeology 97, 49-80.

\section{Ungaro (2007)}

Lucrezia Ungaro, „Il Foro di Augusto \& La memoria dell'antico“, in: Lucrezia Ungaro (Hg.), Il Museo dei Fori Imperiali nei Mercati di Traiano, Roma, I8-169.

\section{Verduchi (1999)}

Patrizia Verduchi, „Rostra Augusti“, in: Eva Margareta Steinby (Hg.), Lexicon Topographicum Urbis Romae, Bd. IV. Roma, 2I4-2I7.

\section{Wallace-Hadrill (1993)}

Andrew Wallace-Hadrill, Augustan Rome, London.

\section{Walter (2004)}

Uwe Walter, Memoria und res publica. Zur Geschichtskultur im republikanischen Rom, Frankfurt a.M.

\section{Welch (2003)}

Katherine Welch, „A new view of the origins of the basilica. The Atrium Regium, Graecostasis and Roman diplomacy“, Journal of Roman Archaeology I6, 5-34.

\section{Welin (1953)}

Erik Welin, Studien zur Topographie des Forum Romanum, Rom.

\section{Zanker (I968)}

Paul Zanker, Forum Augustum. Das Bildprogramm, Tübingen. 


\section{Zanker (1972)}

Paul Zanker, Forum Romanum. Die Neugestaltung durch Augustus, Tübingen.

\section{Zanker (1987)}

Paul Zanker, Augustus und die Macht der Bilder, München.

\section{Bildnachweise}

Abb. I: nach Golvin (2005) 82-83

Abb. 2: nach Welch (2003) 6 Abb. I

Abb. 3: Favro (1996) I97 Abb. 84 (Zeichnung R. Reif)

Abb. 4: nach Stambaugh (I988) II2 Abb. 8 (überarbeitet S. Muth)

Abb. 5: Stambaugh (I988) II5 Abb. 9

Abb. 6: Coarelli (1985) I20 Abb 2I

Abb. 7: Photo Staatliche Museen zu Berlin Preußischer Kulturbesitz, Münzkabinett, Objektnummer I820I844

Abb. 8: Photo CoDArchLab, www.arachne.uni-koeln.de, Mal2729-04

Abb. 9: Photo S. Muth

Abb. Io: Photo Staatliche Museen zu Berlin Preußischer Kulturbesitz, Münzkabinett, Objektnummer I820I342

Abb. II: Kent - Overbeck - Stylow (I973) Taf. I4 Abb 5I

Abb. I2: Photo Staatliche Museen zu Berlin Preußischer Kulturbesitz, Münzkabinett, Objektnummer i82068I9

Abb. I3: Ulrich (1993) 52, Abb. I

Abb. I4: Photo Staatliche Museen zu Berlin Preußischer Kulturbesitz, Münzkabinett, Objektnummer I8202362

Abb. 15: Meneghini u. Santangeli Valenzani (2007) 47 Abb. 36

Abb. I6: nach Meneghini u. Santangeli Valenzani (2007) 44 Abb. 32 (unter Berücksichtigung der Rekonstruktion der Statuenaufstellung nach Spannagel (I999) Taf. I)

Abb. I7: Favro (1996) 23I Abb. 96

Abb. I8: Degrassi (1945-46) 93 Abb. II

Abb. I9: Carafa (1998) 56 Abb. 49

Abb. 20: Photo S. Muth

Abb. 2I: nach Huelsen (1905) Taf. I (überarbeitet S. Muth)

Abb. 22: Stoll (2000) 2I3 Nr. 353

Abb. 23: Huelsen (1905) I32 Abb. 67

Abb. 24: Photo CoDArchLab, www.arachne.uni-koeln.de, Malı298-o 
